THE MORNING AFTER: THE MEXICAN

PESO IN THE AFTERMATH OF THE 1994

CURRENCY CRISIS

Sebastian Edwards

Miguel A. Savastano

Working Paper 6516 


\title{
THE MORNING AFTER: THE MEXICAN PESO IN THE AFTERMATH OF THE 1994 CURRENCY CRISIS
}

\author{
Sebastian Edwards \\ Miguel A. Savastano
}

Working Paper 6516

http://www.nber.org/papers/w6516

\section{NATIONAL BUREAU OF ECONOMIC RESEARCH 1050 Massachusetts Avenue \\ Cambridge, MA 02138 \\ April 1998}

This is a revised version of a paper presented at the National Bureau of Economic Research Conference on Currency Crises, Cambridge, Massachusetts, February 6-7, 1998. The opinions expressed in this paper are exclusively those of the authors, and do not reflect the views of the NBER or of the IMF, its staff, its management or its Executive Board. We thank our discussant, Brad DeLong for helpful comments. We are grateful to Agustín Carstens and Abraham Vela from the Banco de Mexico for their comments, for providing us some of the data, and for helping us clarify a number of issues. Julio Santaella also provided helpful comments. We thank Rajesh Chakrabarti and Stacy Maynes for their able assistance.

(C) 1998 by Sebastian Edwards and Miguel A. Savastano. All rights reserved. Short sections of text, not to exceed two paragraphs, may be quoted without explicit permission provided that full credit, including (C) notice, is given to the source. 
The Morning After: The Mexican Peso

in the Aftermath of the 1994 Currency Crisis

Sebastian Edwards and Miguel A. Savastano

NBER Working Paper No. 6516

April 1998

JEL Nos. F31, F32

\section{ABSTRACT}

The Mexican peso crisis of December 1994 shocked politicians, analysts and pundits. Shock was followed by panic, as investors flew the country. It took a massive bail-out package put together by the IMF and the US Treasury to generate some tranquility in the markets in mid to late 1995. From early on the Mexican authorities stated that stabilizing the value of the peso, within the context of a freely floating exchange rate regime, was one of their most important objectives. During most of 1995 this objective seemed to be highly elusive. Starting in 1996, however, the peso began to exhibit an impressive degree of stability. So much so that a number of analysts began to wonder whether this stability was consistent with a freely floating regime. Some even argued that it was "déjà vu" all over again, and that the Bank of Mexico was manipulating monetary policy in order to artificially maintain a strong peso. In this paper we try to explain the relative stability exhibited by the peso/dollar nominal exchange rate since late 1995. Specifically, we approach this issue from two main angles: First, we ask whether the behavior of the peso/dollar rate since 1995 is broadly comparable or consistent with the behavior of a "typical" floating exchange rate. And our answer to this question was a qualified yes. Second, we explore whether during 1996-97 the Bank of Mexico followed some sort of feedback rule from the exchange rate to monetary policy. Our answer to this question was another qualified yes, but perhaps more strongly qualified than the first one.

Sebastian Edwards

Anderson Graduate School of Management University of California, Los Angeles

Los Angeles, CA 90095 and NBER

sedwards@agsm.ucla.edu
Miguel A. Savastano

Research Department International Monetary Fund

70019 th Street, NW

Washington, DC 20431

msavastano@imf.org 


\section{Introduction}

More than three years after Mexico's exchange rate crisis there are still important questions regarding the country's economic future. In spite of a successful containment policy, and a vigorous recovery of the growth rate, some observers wonder whether this time around Mexico will be able to build the bases for solid and sustainable development. The historical elusiveness of macroeconomic stability in Mexico is at the core of this apprehension. More specifically, a number of observers, both in the private sector as well as in academic circles, have asked if Mexico will finally be able to escape the perverse cycle of failed stabilization attempts and devaluation crises. Exchange rate behavior has been at the center of these discussions. Many analysts have been surprised by the relative stability that the supposedly floating peso/dollar exchange rate exhibited during 1996 and most of $1997 .^{1}$ Others became concerned about the sustained real appreciation experienced by the peso between 1995 and 1997, and some have even asked whether Mexico is once again headed towards a serious crisis triggered by real exchange rate overvaluation (Dornbusch 1997).

Most empirical case studies on exchange rate crises--including those on the Mexican 1994 episode--have tended to emphasize the period leading to the currency collapse. Issues related to the pace of credit creation, asset demand, and current account sustainability, among others, have figured prominently in these studies. Almost no work has been done, however, on the behavior of the exchange rate--and other key macroeconomic variables, for that matter--in the period following a crisis. More concretely, very few studies have focused on the strategies followed by the monetary authorities to stabilize the currency in the aftermath of a major exchange rate collapse. And yet, as the recent East Asian crises have made abundantly clear, it is

\footnotetext{
'See, for example, The Economist, "The Lingering Tequila Hangover", March 14-20, 1998, p 17.
} 
what follows the collapse of the exchange rate what determines the extent of "damage" done by the crisis itself.

This paper deals with the 1994 Mexican crisis and its aftermath. We concentrate on the events leading to the exchange rate collapse in December of that year, and we examine the behavior of some key macroeconomic variables in the three years following the crisis. We are particularly interested in addressing two main questions: First, what have been the forces behind the apparent stability of the peso/dollar exchange rate during 1996-97. And second, what has been the role of Bank of Mexico's (BOM) monetary policy in the post (1996-1997) crisis period. In particular, we are interested in investigating whether, as some analysts have argued, during that period BOM's monetary policy has been geared at maintaining a degree of nominal exchange rate stability that may be at odds with the requirements of a floating rate regime. The paper concentrates on the 1995-97 period and, thus, it does not analyze whther the appointment of anew BOM's governor in early 1998 has resulted in achange in the Bank's monetary policy.

The analysis of the Mexican experience, and in particular the achievement of relative exchange rate stability merely eighteen months after the crisis, should be valuable to students of East Asia. At the time of this writing Thailand, Indonesia, Malaysia, Korea and the Philippines are seeking, with different degrees of success, to contain the crises and bring the free fall of their currencies to an end.

The rest of the paper is organized as follows: Section II deals with the period that preceded the 1994 crisis. We provide a brief overview of developments in 1990-94 and discuss two (implausible) explanations for the collapse of the peso that, interestingly, have resurfaced in the context of the recent East Asian crises. We argue that throughout 1993-1994 most available information suggested that things in Mexico were getting badly out of hand. Most analysts, 
however, badly missed the magnitude of the disequilibrium and, thus, underestimated the required adjustment in the nominal and real exchange rate following the abandonment of the exchange rate band. We argue that the use of inadequate models to evaluate real exchange rate behavior might have been at the core of the generalized inability to gauge the seriousness of the situation. Section III is devoted to analyzing exchange rate behavior in the period following the crisis. We inquire whether during this period the peso/dollar rate has behaved in a manner compatible with a floating exchange rate regime. Our analysis, based on a cross-country comparison of exchange rate volatility measures, as well as on the calibration of a simple monetary model, suggests that throughout most of the 1995-97 period Mexico's exchange rate behavior has been largely consistent with that of (quasi) floating rates. Our analysis, however, is also consistent with the notion that during this period the BOM took into account exchange rate developments for conducting monetary policy. Section IV looks at this issue in greater detail, and focuses on the BOM operating procedures in 1995-97, trying to shed light on the question "What does the Bank of Mexico really do?" Concretely, we use daily and weekly data for 199697 to inquire whether there is evidence suggesting that, when conducting monetary policy, BOM has used some type of feedback rule that takes into account the behavior of the nominal exchange rate. We conclude that, notwithstanding the perils of relying on "noisy" high-frequency data to address that question, there is some preliminary evidence supportive of that view.

\section{The Road to Collapse: 1991-94}

In 1985 , three years after having come close to default on its external debt and having ignited the Latin American debt crisis, Mexico embarked on an ambitious market-oriented reform program. Although this process started slowly, by 1989 it had gathered considerable 
momentum. The overall program, vigorously pushed by the administration of President Salinas de Gortari, had four basic components: ${ }^{2}$ (a) the opening of the economy to international competition; (b) a comprehensive process of privatization and deregulation; (c) a stabilization program centered around a predetermined nominal exchange rate, and supported by restrictive fiscal and monetary policies; and (d) a broad social and economic agreement between the government, the private sector and labor unions--known as the Pacto--aimed at guiding price, exchange rate and wage increases over loosely specified horizons. By 1994, the last year of the Salinas' administration, an impressive number of reforms had been implemented, including the approval of the much publicized North American Free Trade Agreement (NAFTA).

\section{II.1 The Pacto, Capital Inflows and the Exchange Rate}

Mexico's protracted adjustment to the external crisis of 1982 led to an upward ratcheting of the rate of inflation, which reached a historical high of 140 percent per annum in late 1987. At that point, the Mexican authorities decided to confront the inflation problem head on and designed an ambitious stabilization program centered on a temporary freeze of wages and administered prices agreed in the context of the Pacto. A few weeks after the launching of the program, in late February 1988, the nominal exchange rate was fixed and became the main anchor of the anti-inflationary effort. ${ }^{3}$ Between 1988 and 1994 the authorities made several modifications to the exchange rate system, moving first, in 1989 , to a regime based on a preannounced rate of devaluation--where the rate of devaluation was set below the (actual and expected) rate of inflation, and in November 1991 to a (narrow) exchange rate band with a

\footnotetext{
${ }^{2}$ For a detailed account of Mexico's reform program see Aspe (1993) and Lustig (1992). See also Loser and Kalter (1992).

${ }^{3}$ For comprehensive analyses of the Mexican stabilization program of 1988 see Vela (1993) and Santaella and Vela (1996). See also Aspe (1993).
} 
sliding ceiling. From early 1992 to October 1993--when the NAFTA controversy heated up in the United States--the nominal peso/dollar rate was remarkably stable, and invariably remained in the lower half of the band. Throughout most of this period, Mexico's managed exchange rate regime was supported by prudent fiscal and monetary policies.

The rate of inflation fell drastically (to less than 20 percent) in the first 18 months of the program, but from then on the pace of disinflation became painfully slow. As had happened a decade earlier in Chile, and in other stabilization episodes, the attempt to reduce inflation using the exchange rate as the main nominal anchor gave rise to a substantial and protracted real appreciation of the Mexican peso (see Figure 1). ${ }^{4}$ Already in 1989 a number of observers argued that this trend would become unsustainable, as the country lacked sufficient foreign exchange reserves to finance the rapidly growing current account deficit (Edwards 1998b).

In early 1990, after arduous negotiations, the Brady debt reduction agreement was finally signed, the authorities accelerated the pace of their ambitious structural reform program, and foreign investors rediscovered Mexico. The ensuing surge in private capital inflows allowed Mexico to finance current account deficits of the order of 7 percent of GDP in 1992-94; all along the real exchange rate continued to appreciate, and output growth remained subdued.

In 1992 a public debate began to take place on the consequences of the real appreciation that the peso had experienced since the 1988 stabilization. In early 1992 Dornbusch claimed that "[t]he current problem of the Mexican economy is the overvalued exchange rate" (reproduced in Dornbusch (1993), page 369), and in November of that year he argued that the daily rate of devaluation of the peso had to be tripled in 1993 to 120 cents per day (Excelsior, November 23,

\footnotetext{
4 In this figure, and throughout the paper, a decline in the real exchange rate indicates a real appreciation. For a comparison of ther Chilean and Mexican stabiliozation programs see, for example, Edwards (1998a).
} 
1992, p.1). Also the World Bank, in its 1993 Trend in Developing Economies, noted that in Mexico "[g]rowth recovery has ... been modest ... [an outcome that] can be traced to a combination of slow productivity growth, a weak US economy, tight fiscal and monetary policies, and real exchange rate appreciation" (pages 325-30, emphasis added). The Mexican authorities responded to these apprehensions with a rehashed version of the "Lawson doctrine" and argued that, since the capital inflows were largely private and the fiscal accounts were in surplus, there was nothing to be concerned about. The authorities "substantiated" their view arguing that rapid increases in productivity that would lead to a strong export expansion, and thus to a narrowing of the current account, were about to take place, and stressing that the exchange rate bands and the freely determined interest rates gave enough flexibility to their monetary policy to deal with eventual disruptions in the flows of capital. ${ }^{5}$ Confident that the approval of NAFTA in late 1993 and the entry to the OECD scheduled for 1994 were a tribute to the sound fundamentals of the Mexican economy, the authorities announced an economic program for 1994, a year of presidential elections, that envisaged single-digit inflation, a pick-up in output growth and no fundamental change in the core of macroeconomic policies.

The size and pace of the capital inflows that Mexico was absorbing since 1991 gave rise to the notion that the accompanying strengthening of the peso represented an "equilibrium" movement of the real exchange rate that was fully justified by fundamentals. The view that an increase in capital flows will lead to an appreciation of the real exchange rate is of course correct from a simple theoretical perspective. Indeed, in order for the transfer of resources implied by a higher capital inflows to become effective, a real appreciation is required. A problem with this interpretation, however, is that it overlooks that the rate at which capital was flowing into

s See Banco de Mexico (1993, 1994), Aspe (1993) and Ortiz (1994). 
Mexico in 1992-94--i.e., at 7 percent of GDP per annum--was clearly not sustainable in the long run. Considerations of external solvency and current account sustainability indicate unequivocally that flows of this magnitude at some point have to decline, and that such a decline will encompass a reversal of the real exchange rate appreciation. ${ }^{6}$ Interestingly enough, even those analysts that recognized the unsustainable nature of the capital flows badly miscalculated the required real exchange rate adjustment. Indeed, in early 1994 the debate among Mexicoskeptics was whether a 20 or a 30 percent devaluation would be required to reestablish equilibrium. ${ }^{7}$ Very few, if any, observers would have predicted that merely a year after having abandoned the band, the peso would have lost almost one half of its value. This inability to grasp the seriousness of the Mexican situation (both before and after the collapse) clearly illustrates the shortcomings of the models commonly used by both private sector and academic analysts to assess the adequacy of real exchange rates. Indeed, most of these models are strictly based on flows considerations--and some of them are little more than glorified versions of PPP-and ignore the interaction between flows and stocks. ${ }^{8}$ Models that, on the other hand, pay attention to stocks in general and to the foreign demand for securities issued by emerging markets in particular are, in principle, better equipped to gauge the magnitude of the disequilibrium in circumstances where credibility collapses (Calvo 1994, 1995).

\section{II.2 Mexico in 1994: Two implausible stories}

Few episodes of currency crises have received as much attention in the economic literature as that of Mexico in $1994 .{ }^{9}$ And yet, full three years after the fateful event, it can

6 On the issue of current account sustainability see Reisen (1995) and Milesi-Ferreti and Razin (1996).

7 See Edwards (1998b) for a detailed account of the evolution of different views on Mexico during 1994.

- See Williamson (1995) for a discussion of some of these models.

${ }^{9}$ Analyses of the Mexican crisis can be found in Calvo (1995), Calvo and Mendoza (1996), De Long et al. (1996), Dornbusch et al. (1995), Edwards (1996), Edwards et al. (1996), Edwards (1997), Gil-Díaz and Carstens (1996), IMF (1995a, 1995b), Krugman (1995), Leiderman and Thome (1995), Lustig (1995), Masson and Agenor (1996), 
hardly be argued that there is consensus on what caused the December 1994 devaluation of the peso or, more precisely, on what was the (approximate) contribution of the various hypotheses put forward to explain the occurrence, timing, and size of the peso collapse. One reason for this state of affairs is that many of the earlier accounts of the Mexican crisis, in their quest for extracting quick "lessons" and apportioning blame, searched for simple explanations and sought a single culprit. As pointed out by Edwards et al. (1996) and others, however, this episode was highly complex and defied simple explanations. Indeed, as in the old high school exam, the answer to "What caused the Mexican crisis?" will oftentimes be "All of the above."

It is beyond the scope of this paper to revisit developments in Mexico during 1994 and/or to assess, with the benefit of hindsight, the relative validity of the various hypotheses advanced to explain the December devaluation. ${ }^{10}$ But we will take issue briefly with two rather extreme views that, interestingly, have regained prominence with the unfolding of the 1997-98 East Asian currency crises. The first one is the view that ascribes a negligible role to policy mistakes in the unraveling of the Mexican crisis. This view, endorsed by the Bank of Mexico (BOM) since the very beginning ${ }^{11}$, attributes the occurrence (and size) of the collapse of the peso to the combination of a sequence of adverse and unexpected shocks (domestic and foreign) and various sources of multiple equilibria that gave rise to a self-fulfilling run on the currency (Reynoso (1995); Gil-Díaz and Carstens (1996)). The second one, more popular in financial circles, is the view that ascribes a central role to the incomplete information that was made available to foreign

Obstfeld and Rogoff (1995), Reynoso (1995), Sachs et al. (1996), Warner (1997) and Werner (1996). A more complete list would include most of the studies contained in the July 1996 special issue of the International Journal of Finance and Economics, in the July 1996 special issue of Open Economies Review and in the November 1996 special issue of the Journal of International Economics.

${ }^{10}$ For a comprehensive discussion of developments leading to the crisis see Edwards (1997). See also IMF (1995a, 1995b) and Sachs et al. (1996).

"See, for example, the January 31, 1995 article in The Wall Street Journal by (former) Governor Mancera "Don't Blame Monetary Policy" (page...). 
investors--in particular, to the paucity and unreliability of official data on key economic variables--in triggering the speculative attack(s) on the peso. ${ }^{12}$

A careful examination of the Mexican episode does not provide strong support to any of these two "stories." Let's start with the second one. In the aftermath of the crisis Wall Street analysts and operators argued that the lack of current information on Mexico's international reserves position played an important role in magnifying the crisis. In fact, a post mortem of the crisis sponsored by the Council of Foreign Relations and undertaken by an independent task force chaired by John Whitehead concluded that "[f]ull financial information was not forthcoming to all investors" (page 27). However, there are at least three pieces of evidence that are at odds with the claim that markets didn't know (or, more precisely, couldn't know) what was going on in Mexico in 1994.

First, markets were fully aware (and even supportive) of what turned out to be a crucial modification of Mexico's monetary policy in 1994: the April decision to replace maturing pesodenominated Cetes with the infamous Tesobonos--short-term dollar-linked public debt instruments. This strategy was quite transparent, and was even commented on, matter of factly, in financial circles. For example, JP Morgan's Emerging Markets Outlook of July 22, 1994 noted that "[h]alf of the 28-day and 91-day Cetes offered were issued; the central bank would not accept the high yields required by the market to auction the full amount...In the Tesobonos auction, yields ...trended down modestly..." (page 22). And on July 23, 1994 an article in The Economist pointed out that "[t]he central bank has also had to issue plenty of tesobonos--dollarlinked bonds that are popular with investors that worried about currency risk."13

\footnotetext{
York, 1995.

13 "Pounding the peso", The Economist, July 23, 1994, page 76.
}

${ }^{12}$ See, for instance, the report “Mexico: Why Didn't Wall Street Sound the Alarm?” Group of Thirty, New 
Second, the public and academic debates on the sustainability of Mexico's external position grew louder during the first half of 1994 . For instance, in a much publicized piece prepared for the Spring meetings of the Brookings Institution Economics Panel, Dornbusch and Werner (1994) argued that the Mexican peso was overvalued by at least 20 percent, and urged the Mexican authorities to rapidly find a way to address the problem. These concerns were echoed, albeit on different grounds, by the two prominent discussants of the paper: Guillermo Calvo and Stanley Fischer (Calvo (1994); Fischer (1994)). Financial analysts were also aware that the U.S. authorities' decision to extend a US\$ 6 billion swap facility to Mexico announced on March 24, one day after the Colosio assassination, reflected the serious concerns that those authorities had about the loss of international reserves that the BOM had suffered in the tumultuous first quarter of $1994 . .^{14}$

And third, documents released to the U.S. Senate Banking Committee during 1995 indicate quite clearly that the U.S. Treasury was able to keep track of the evolution of Mexico's international reserves throughout $1994 .{ }^{15}$ For example, a mid-May 1994 memorandum from Assistant Secretary Shafer pointed out that the BOM had, reportedly, spent US\$10 billion since the Colosio assassination to defend the peso. Similar documentation show that Treasury officials were well aware of the speed at which Mexico's reserves were being depleted in the last weeks of the year. ${ }^{16}$ Even though the BOM had maintained during 1994 its longstanding practice of releasing to the public data on its international reserves only three times a year (in April, October and November) there is no compelling reason why diligent analysts in the private sector could not have produced estimates of Mexico's international reserves as accurate as those of the U.S.

\footnotetext{
${ }^{14}$ See, for example, the front page stories in the Financial Times of March 26 and 28, 1994.

is See the D'Amato papers (D'Amato (1995)).

${ }^{16}$ See, for example, the memoranda dated November 18 and December 5 in D'Amato (1995).
} 
Treasury on the basis of available information (on the stocks and flows of Cetes and Tesobonos, trade flows, and so on). Why so many of them did not do it, or if they did, why they did not react earlier to the deterioration of Mexico's external indicators remains an open question. But, in light of the above evidence, it is hard not to conclude that, until the very end, foreign investors simply underestimated the probability of a crisis. ${ }^{17}$

The flaws of the first view -- the "bad luck" view -- become apparent when one examines the policy response to the sequence of shocks that hit Mexico during 1994. As noted earlier, a crucial decision in the area of monetary and exchange rate policy prior to the December crash was taken in April 1994, when the Mexican authorities, in response to the increasing difficulties they were facing for rolling over its sizable stock of peso-denominated debt at the (high) yields prevailing at the time ${ }^{18}$, decided to stave off further rises in domestic interest rates by substituting maturing Cetes for dollar-linked Tesobonos while leaving intact the other two pillars of their monetary policy framework--i.e., the exchange rate band and the target for nominal base money (and, hence, the sterilization of reserve flows). BOM officials have argued that they had followed a similar strategy in late 1993, when the peso came under pressure due to uncertainties about the ratification of NAFTA by the U.S. Congress, and, thus, that "[i]t was natural to follow the same strategy after the Colosio assassination" (Gil Díaz and Carstens (1996), page 168). A problem with this line of reasoning, however, is that it ignores the fact that there is a fundamental difference between using debt swap operations to smooth transitory hikes in interest rates, and using those operations to keep interest rates below their equilibrium level for a prolonged period of time. The tightening of monetary conditions in the U.S. in early 1994--which had raised the

\footnotetext{
$"$ The results obtained by Masson and Agenor (1996) provide further support to this conclusion.

${ }^{18}$ Interest rates on 28-day Cetes had almost doubled between February and mid-April, when they reached a level of about 18 percent per annum in the secondary market.
} 
floor for Mexican rates--and the rapid pace at which maturing Cetes were being replaced for Tesobonos several months after the policy had been adopted ${ }^{19}$ should have made it clear to BOM officials that their debt strategy was achieving the latter rather than the former. Moreover, the decision to maintain the course of policies unaltered after the August presidential election and after the internal debate that preceded the renewal of the Pacto in September leaves little doubt that the authorities deliberately opted for a policy stance which they hoped would enable them to continue lowering interest rates and preserve the exchange rate band.

One can only speculate about the reasons that led the authorities to miss these propitious opportunities to correct the stance of monetary and exchange rate policy. By the third quarter of 1994, Mexican authorities might well have been under the impression that they had weathered off the worst of the speculative pressures and that it was a matter of time before capital inflows would resume at a pace similar to that of 1992-93. Concerns about the adverse effects that higher interest rates (or a depreciation of the peso) might have had on the deteriorating situation of the banking system are also likely to have played a role; ${ }^{20}$ indeed, the decision to preserve the policy stance could have reflected an attempt to buy additional time to work out a plan to strengthen those financial institutions considered to be in a particularly weak position. ${ }^{21}$ Whatever the reasons, there is no question that the Mexican authorities seriously underestimated the risks embedded in their chosen course of action. It is quite a stretch to claim, as BOM officials have

\footnotetext{
${ }^{19}$ Between end-March and end-October the stock of Tesobonos outstanding increased by almost the same amount as the decline in the stock of Cetes (around US\$ 13 billion).

${ }^{20}$ The preoccupation for the financial health of the recently privatized banks had begun in late 1992, when a significant increase in the past due loans ratio became evident. In 1990, non-performing loans--which prevailing regulations defined as unpaid installments of principal plus interest, rather than the total value of the loan--were estimated to be only 2 percent of total loans; that ratio increased to 4.7 percent in 1992, to 7.3 percent in 1993, and to 8.3 percent at the end of the first quarter of 1994.

${ }^{21}$ In fact, by end-June 1994 the federal government banks had designed a debt-relief program comprising a combination of write-offs of commercial banks past due interest and government-issued loan guarantees.
} 
done since the beginning, that this error in judgement (even if well intentioned) does not fall squarely in the category of policy mistakes.

Between June and November 1994 the stock of Tesobonos outstanding had more than doubled to a total of US\$ 16 billion. By end-November BOM's international reserves, at US\$ 12.9 billion, were barely enough to cover 40 percent of total short-term public debt or 10 percent of total short-term liabilities of the banking system. The situation had long surpassed the current account and peso overvaluation sphere and had all the makings of a major financial crisis. It took little to cross the threshold. Few days after President Zedillo was sworn into office (on December 1) news about renewed tensions in Chiapas led to a further attack on the peso, and on December 20, when international reserves had fallen to about US\$10 billion, the authorities finally opted for a policy correction and lifted by 15 percent the ceiling of the exchange rate band. To everyone's surprise, the announcement of the new exchange rate ceiling was not accompanied by other supportive changes in macroeconomic policies or a by a revision of the macroeconomic assumptions for 1995 that had been made public a few weeks earlier. In disbelief, investors--both foreign and domestic--fled, rendering the change in policy ineffective; in one day the BOM lost US\$ 4 billion of reserves. By then, the authorities realized that they had no alternative but to let the peso float. But, as will be seen, the mayhem had just started.

\section{The Mexican Peso since 1995: A Freely Floating Exchange Rate?}

The behavior of the Mexican peso has been a source of concern for analysts and observers since the crash of December 1994. These concerns have varied widely, both across quarters and over time. In the immediate aftermath of the December devaluation, most of the discussion centered around the possibility that a spiraling collapse of the peso would unleash an 
inflationary explosion that would wreak havoc with the real economy and the financial system. By late-1995 the reasons for concern started to change, as several observers became wary about what they considered a surprising--and some argued, even unwarranted--stability of Mexico's nominal exchange rate. This concern gained enormous strength during 1996 and mid 1997. Many analysts were particularly surprised by the fact that, even though the annual inflation rate was falling rather slowly from its 52 percent peak in December 1995 and had remained in the double digits during 1996-97, the peso/dollar exchange rate by, say, mid-October 1997 (7.71 Mex\$/US\$ on October 21) was essentially at the same level it had been in early January 1996--see Figure 2A. During this period there seemed to be a growing consensus that the relative stability of the nominal exchange rate in a context of double-digit inflation was more the result of measures undertaken by the BOM--allegedly to "smooth out" short-term fluctuations--than the outcome of market forces.

In its October 3, 1997 Emerging Markets Data Watch JP Morgan stated that "[b]y staying at about NP7.8 throughout 1997 so far, the peso's behavior has reopened the debate on whether it is appreciating too much in real terms...Peso strength has gone further, and lasted longer than we had envisaged [in] our earlier forecasts" (page 3). This influential financial newsletter went on to say that the surprising strength of the peso was likely to be the result of a deliberate Bank of Mexico policy stance. Other observers went a step further and saw in the stability of the nominal exchange rate, and the associated appreciation of the real exchange rate in 1996-97 (Figure 2B), signs of another cycle of policy-induced overvaluation of the peso that could lead to yet another episode of slow growth and over borrowing culminating in a major currency crisis similar to those that had affected the country during the last 25 years (Dornbusch 1997). More recently, The Economist $(1998, \mathrm{p} .17)$ has argued that the BOM policy stance towards the peso has been 
influenced by political considerations: " $[D]$ istrastful investors have wondered aloud wether the central bank -- which lost much credibility with the collapse -- really enjoys independence...[T]he doubters have noted that the government's policy on the peso, which is theoretiucally free to float, has actually been seyt by a commitee..."

Most analysts that have expressed concerns about the behavior of the Mexican peso have not been explicit, however, about the counterfactual--i.e., about the type of behavior the peso should have exhibited if it really were floating freely. Some may argue that the dismal performance of "traditional" exchange rate models to explain and predict short-term movements of floating exchange rates in the last two decades (Frankel and Rose (1995); Isard (1995)) exempts observers from the need to provide some theoretical or empirical support for their concerns. We disagree. For one thing, many of the recent worries about the real overvaluation of the peso seem to be grounded on the notion that either some type of PPP-adjustment or a simple flow-based RER equations -- not too different from those used to evaluate the appropriateness of Mexico's RER in 1993-94 --, provide reasonable yardsticks to assess the behavior of a floating exchange rate over relatively short periods. However, the notion that exchange rate analyses rooted on PPP are useful for this purpose has been flatly rejected by numerous empirical studies (Froot and Rogoff (1995); Isard (1995)). Moreover, as we argued in the previous section, simple real exchange rate models that focus on flows and disregard the behavior of stock variables can produce highly misleading estimates of the degree of real exchange rate misalignment at a particular moment in time, especially under a floating regime.

Twenty-five years of experience with floating exchange rates have produced a substantial body of evidence on their short and long-term empirical regularities (Baillie and McMahon (1989); de Vries (1994)) that cannot be simply dismissed when passing judgement on the 
evolution of a particular float--even if this happens to be the Mexican peso. The analysis in this section attempts to place the debate about the recent behavior of the Mexican peso on firmer grounds. Specifically, we explore whether -- and to what extent -- the behavior exhibited by Mexico's nominal exchange rate vis-a-vis the U.S. dollar in 1995-97 conforms with the behavior of other floating rates. To address this question we conduct two types of exercise, one based on a cross-country comparison of simple measures of nominal exchange rate volatility, and the other one focused on the evolution over time of various "fundamental determinants" of the peso/dollar exchange rate.

For the first exercise we used daily data on the nominal exchange rate vis-a-vis the U.S. dollar of the currencies of Germany, Japan, United Kingdom, Canada, Australia, New Zealand and Mexico, and on the nominal exchange rate vis-a-vis the German deutschemark of the French franc, for the period January 1991-November 1997 (about 1800 observations per currency). ${ }^{22}$ We calculated the day-to-day percentage change of the eight nominal exchange rates over the whole sample (Figures 3A-3C) and then computed, for each calendar year, two measures of short-term volatility often used in empirical analyses of nominal exchange rates: (i) the mean absolute value of the day-to-day percentage change and (ii) the standard deviation of the (actual) day-to-day percentage change (see Baillie and McMahon (1989)). We also computed these two measures of volatility for the weekly (end-of-week) and monthly (end-of month) percentage change of the eight nominal exchange rates during the period.

The results of these computations are presented in Tables 1-3. These tables reveal three important features of the recent behavior of the Mexican peso: (1) the peso/dollar exchange rate was considerably less volatile than the other seven exchange rates in the period prior to the

\footnotetext{
${ }^{22}$ The exchange rates used for these calculations consist of the "representative rates" submitted daily by all countries' central banks to the Treasurer's Department of the IMF.
} 
devaluation of December 1994 (January 1991-November 1994); (2) the Mexican peso exhibited the highest degree of short-term volatility among this group of currencies in 1995; and (3) the short-term volatility of Mexico's nominal exchange rate has been broadly in line with that of the other seven currencies in the last twenty-three months of the sample (January 1996- November 1997). The first two findings are hardly surprising: as noted earlier, Mexico's exchange rate system prior to the devaluation consisted of a gradually crawling band with relatively narrow margins in which the central bank intervened heavily to dampen (most) short-term fluctuations, whereas the financial mayhem that beset Mexico in the first quarter of 1995 was reflected primarily in wild daily gyrations in the value of the peso--which were greater than 6 percent (in both directions) on several occasions (Figure 3B). The third feature, however, is quite interesting. According to the statistics in tables 1-3, in 1996-97 the Mexican peso was consistently more volatile than the Canadian dollar and the French franc ${ }^{23}$ and, while it was more stable than the currencies of the G-3 and the United Kingdom (countries widely regarded as having the "cleanest" type of float), exhibited a degree of volatility comparable to that of the currencies of Australia and New Zealand (Figure 3D). This evidence, therefore, suggests that the relative stability of Mexico's nominal exchange rate in the recent period has not been "excessive" or unusual for a floating rate. At the same time, however, the fact that the peso/dollar rate has exhibited a degree of volatility lower than that of the "cleanest" floaters in the group is not inconsistent with the view that the BOM has taken into account, in an assymetric way, the behavior of the nominal exchange rate when conducting monetary policy during this period.

\footnotetext{
${ }^{23}$ We decided to include the franc/DM exchange rate in the sample despite the fact that the French currency has not floated freely during the period under study (but has instead been linked, through the ERM and monetary policy, to the evolution of the German deutschemark) in order to have comparable data on a country with a managed float where exchange rate stability has been a primary objective of monetary policy.
} 
Of course, it is possible that by comparing the mean absolute value and standard deviation of high-frequency exchange rate changes during specific calendar years we are imposing arbitrary restrictions on the distribution of nominal exchange rates that prevent us from detecting important peculiarities of the behavior of the Mexican peso. In particular, it may be the case that the volatility measures of the Mexican peso for the years 1996-97 (and even 1995) are unduly influenced by large "volatility clusters" (de Vries (1994)) and that, except for a few days (or weeks) with very large exchange rate fluctuations, the nominal peso/dollar rate is "excessively" stable for the most part of the year. To explore whether this is in fact the case, we broke down the sample for the years 1995-97 into "turbulent" and "calm" periods for each exchange rate. Specifically, we used the day-to-day percentage changes to construct monthly measures of volatility for each currency and ranked them in descending order. We then used the observations from the three months of each year where volatility was highest for each exchange rate to compute the volatility measures for the "turbulent" period, and the observations from the other nine months to obtain the corresponding measures for the "calm" period of the year. The outcomes of these calculations are reported in Table 4. Overall, the results are quite similar to those we obtained using all the observations for each calendar year: the Mexican peso still stands out as the most volatile currency in this group in 1995 (both in the "turbulent" and "calm" periods), and, perhaps more important, the volatility of the peso/dollar exchange rate continues to be higher than that of the Canadian dollar and the French franc--and of a magnitude similar to that of the New Zealand dollar--in the "calm" periods of 1996-97. Hence, these findings support our earlier conclusion: the relative stability exhibited by the Mexican peso over many intervals in 
recent months is not at odds with the behavior of exchange rates in other countries generally regarded as having (some variant of) a floating exchange rate arrangement. ${ }^{24}$

There is, however, one aspect of the behavior of the Mexican peso captured by the indicators in Table 4 that seems rather peculiar, namely the marked shift in the (relative) degree of volatility between "turbulent" and "calm" sub-periods. In fact, unlike the other currencies, which more or less preserve their pecking order in the scale of volatility in both sub-periods, the peso/dollar exchange rate jumps ahead in the scale of volatility in turbulent periods. Indeed, Table 4 shows that the degree of volatility of the peso/dollar rate during these sub-periods was comparable to that of the three most volatile exchange rates in the sample (i.e., the DM/dollar, yen/dollar, and pound/dollar rates). These large shifts in the (relative) degree of volatility across sub-periods ${ }^{25}$ might be a reflection of a different ("atypical") underlying distribution of nominal exchange rate changes for the Mexican peso or of differences in the relationship between the nominal exchange rate and other financial variables (e.g., interest rates) in the case of Mexico. We will come back to this issue later on in the paper.

For the second exercise we followed the methodology developed by Rose (1994) and Flood and Rose (1995) to analyze the relationship between exchange rate volatility and macroeconomic volatility across exchange regimes. The methodology serves to ascertain whether the increase in exchange rate volatility brought about by a switch from a fixed (managed) to a floating exchange rate regime is associated with a corresponding increase in macroeconomic volatility. To the extent that this is the case, "standard" macroeconomic fundamentals can be said

\footnotetext{
${ }^{24}$ Werner (1997) reaches a similar conclusion.

${ }^{25}$ These shifts are also clear when one compares the ratio between the measures of volatility in "turbulent" and "calm" periods. With the exception of Mexico, these ratios are quite similar across countries and over time (in the order of 1.5-1.6-- and none, except for two, greater than 2). In the case of Mexico, however, these ratios are much larger than 2 in 1995 and 1997 , and in the order of 1.8 in 1996.
} 
to account for the high exchange rate volatility that characterizes floating rates (as the Mexican peso in 1995-97). Conversely, if macroeconomic fundamentals do not change systematically across exchange regimes one would have to conclude that the sources of the increased exchange rate volatility in a float are not macroeconomic in nature (this is, in fact, the main conclusion of Flood and Rose's analysis of the behavior of the nominal exchange rates of eight OECD economies before and after the breakdown of Bretton Woods). The methodology is useful for identifying potential fundamental determinants of exchange rates and is grounded on sound economic intuition. Simply put, it combines the fact that theoretical models typically assume that there exists a regime-invariant (linear) link between (nominal) exchange rates and "fundamentals," with the empirical observation that the conditional volatility of exchange rates rises sharply whenever a previously fixed or managed exchange rate is allowed to float. The testable corollary of these two premises is that any variable that is to be considered a potentially valid fundamental determinant of exchange rates also has to exhibit a significant increase in its conditional volatility with the switch from a fixed to a floating exchange regime.

The mechanics of the exercise are fairly straightforward. In the case of the simple flexible-price monetary model of the exchange rate, the exercise starts from the three standard equations: (a) a structural money market equilibrium condition for the domestic country:

$$
m_{1}-p_{t}=\beta y_{t}-\alpha i_{t}+\epsilon_{t}
$$

where $m_{t}$ is the (natural logarithm of the) money supply in period $t, p_{t}$ is the (log of the) price level, $y_{t}$ is (the log of ) real income, $i_{t}$ is the nominal interest rate, $\epsilon_{1}$ is a money demand shock, and $\alpha$ and $\beta$ are structural parameters; (b) a comparable equilibrium condition for the foreign country:

$$
m^{*},-p^{*}=\beta y_{1}^{*}-\alpha i_{1}^{*}+\epsilon_{1}^{*}
$$


that assumes elasticities for real income and the interest rate that are equal to those of the home country; and (c) the assumption that PPP holds, at least up to a disturbance:

$$
p_{t}-p^{*}{ }_{t}=e_{t}+v_{t}
$$

where $e_{t}$ is the (log of the) nominal exchange rate (units of domestic currency per unit of foreign currency) and $\nu_{t}$ is a stationary disturbance. And then combines (a) through (c) to obtain the familiar exchange rate equation:

$$
e_{t}=\left(m-m^{*}\right)_{1}-\beta\left(y-y^{*}\right)_{t}+\alpha\left(i-i^{*}\right)_{1}-\left(\epsilon-\epsilon^{*}\right)_{t}-v_{t}
$$

which can also be expressed as:

$$
e_{t}-\alpha\left(i-i^{*}\right)_{1}=\left(m-m^{*}\right)_{1}-\beta\left(y-y^{*}\right)_{1}-\left(\epsilon-\epsilon^{*}\right)_{1}-v_{1}
$$

In the case of other structural exchange rate models (e.g., sticky-price models, portfoliobalance models, currency substitution models) the procedure would be similar, namely obtain the reduced-form relation for the nominal exchange rate implied by the model, and then exploit the fact that the left-hand side and right-hand side of that relation represent, in theory, alternative ways of measuring the same latent variable: the "fundamental determinants" of the exchange rate. For example, Flood and Rose (1995) explicitly consider the alternative case of a sticky-price model à la Frankel (1979) that relaxes the PPP assumption. Another alternative that would seem relevant for small developing economies--such as Mexico--would be a model that relaxes the assumption that monetary services are provided only by the domestic currency and, hence, allows a role for currency substitution in the determination of the exchange rate. A problem with these alternatives is that there are multiple empirical specifications of their corresponding reduced-form equations and therefore it is far more difficult to rely on the empirical literature to make reasonable assumptions about the values of the structural parameters necessary to 
implement the procedure. Thus, to simplify matters, and as a first approximation, we decided to stick to the familiar flex-price monetary model.

Flood and Rose (1995) call the left-hand side of equation (3') the "virtual fundamentals" (VF):

$$
\mathrm{VF} \equiv e_{t}-\alpha\left(i-i^{*}\right),
$$

and the first two terms of the right-hand side the "traditional fundamentals" (TF):

$$
\mathrm{TF} \equiv\left(m-m^{*}\right),-\beta\left(y-y^{*}\right),
$$

they also consider a variant of equation (5) that includes the term for money disturbances and call it "augmented traditional fundamentals" (ATF):

$$
\mathrm{ATF} \equiv\left(m-m^{*}\right),-\beta\left(y-y^{*}\right),-\left(\epsilon-\epsilon^{*}\right),
$$

which, using (3), can be shown to be equal to:

$$
\mathrm{ATF} \equiv\left(p-p^{*}\right),-\hat{\alpha}\left(i-i^{*}\right),
$$

The thrust of this approach consists of comparing the time series characteristics of VF, TF and ATF (the only difference between the latter two being the money disturbance term $\left.\left(\epsilon-\epsilon^{*}\right)_{l}\right)$. As noted above, the underlying hypothesis is that if the model describes reality "well," "virtual" and "traditional" fundamentals should exhibit similar time series properties. If they do not, then either the model is faulty, measurement errors are pervasive, or both. To deal with the possible non-stationarity of the data, Flood and Rose (1995) propose using the conditional volatility (i.e., the standard deviation of the first difference of VF, TF and ATF) as the metric for the comparison. They also stress that the methodology does not require making strong assumptions about the processes of the forcing variables (including, in particular, assumptions about exogeneity); all it requires, aside from the raw economic data, is making 
"reasonable"--i.e., empirically sound--assumptions about the values of the structural parameters $\alpha$ and $\beta$.

To apply this methodology to the peso/dollar exchange rate we used monthly data for Mexico and the U.S. for the period January 1991-October $1997 .^{26}$ We assumed that Mexico was the domestic country, and used the consumer price indices to measure prices, narrow money (M1) data to measure the money supply, industrial production indices as a proxy for real income, and the return on one-month treasury bills as interest rates. ${ }^{27}$ All the series were transformed by natural logarithms, except for the interest rates--which were measured as nominal rates divided by 100 . Following Flood and Rose (1995), we chose $\alpha=0.5$ and $\beta=1.0$ as the benchmark values in the computation of VF, TF and ATF, and checked the sensitivity of the results to two alternative values for $\alpha(0.1,1.0)$ and $\beta(0.5,1.5)$.

Figure 4 shows the plots of the levels (left column) and first differences (right column) of the three measures of the fundamentals of the peso/dollar exchange rate using the benchmark values $\alpha=0.5$ and $\beta=1.0$ for the period January 1991-June/October 1997. Since we are interested in the conditional innovations of the fundamentals--more precisely, in comparing those innovations before and after the devaluation of December 1994--the plots of the first differences are the objects of greatest interest. ${ }^{28}$ Visual inspection of the plots suggest, first, that the volatility of the "virtual fundamentals" of the Mexican peso increased markedly following the December 1994 devaluation; second, that the volatility of the "augmented traditional fundamentals" was also higher in the period following the devaluation; and third, that the volatility of the

\footnotetext{
${ }^{26}$ All the data for this exercise were extracted from the IFS. For a few series--e.g., industrial production indices-the latest observations available were June 1997.

${ }^{27}$ We also used monetary base in this analysis. The results where essentially the same.

${ }^{28}$ If the fundamentals follow a random walk--as conventional unit-root tests applied to high frequency data on the underlying variables typically suggest (see section IV.2)--then the first difference is also the innovation.
} 
"traditional fundamentals" did not change systematically after the adoption of a floating exchange rate. The first and last features are broadly in line with the findings of Flood and Rose (1995) for their sample of eight OECD economies (and the first one is also consistent with our earlier analysis of the volatility of the peso/dollar rate). However, the second feature--the fact that the volatility of ATF increased after the devaluation--seems at odds with the results obtained by Rose (1994) and Flood and Rose (1995).

The information contained in these plots can be analyzed more rigorously with the help of Table 5. The table presents estimates of the standard deviation of the first differences of VF, ATF and TF for the whole period, as well as for the periods before and after the December 1994 devaluation, for different values of the parameters $\alpha$ and $\beta$. In addition, the last column contains estimates of the ratio of the standard deviation of the first differences of fundamentals in the period following the devaluation (the floating period) to the standard deviation of the corresponding variable in the period prior to the devaluation. ${ }^{29}$ The estimates in the table supports our interpretation of the plots in Figure 4. The sample standard deviations show a marked increase in the level of volatility in the series of VF and ATF since the devaluation of December 1994 for all values of $\alpha$, and similar levels of volatility across periods for all the series of TF. In fact, the estimates of the "volatility ratio" in the last column indicate that the null hypothesis of no increase in conditional volatility during the float is rejected for all the VF series and all the ATF series at any reasonable level of statistical confidence, while such hypothesis cannot be rejected for any of the TF series. This basic result did not change when we computed

\footnotetext{
${ }^{29}$ Following Flood and Rose (1995) we report the ratio of standard deviations rather than the corresponding F-statistics to highlight those cases were fundamental volatility was actually lower during the float than in the previous period. The relevant $F$ statistic can be obtained by squaring the ratio presented in the table (provided that the ratio is greater than 1). Of course, the ratio of regime-specific sample variances that will be obtained by this procedure, suitably adjusted by degrees of freedom, will be distributed as $F$ only if the first differences of the fundamentals are normally distributed (which may not be the case).
} 
the standard deviations (and the volatility ratio) excluding December 1994 and some or all the observations for 1995 from the second sub-sample--although in these cases the increase in the level of volatility of the VF and ATF series were considerably smaller. ${ }^{30}$

These results suggest that, in contrast with the OECD experiences examined by Flood and Rose (1995), the increase in the level of volatility of the "virtual fundamentals" of the peso/dollar rate during the current float was accompanied by an increase in the level of volatility of (some) macroeconomic fundamentals. Put it differently, in the case of Mexico the evidence to date does not rule out completely the possibility that the determinants of nominal exchange rate volatility in 1995-97 are of a macroeconomic nature. That being said, the evidence also indicates that the likely sources of the increase in macroeconomic volatility in the recent period have been shocks to the (relative) money demand--which, as we noted earlier, is the only difference between TF and ATF. We find this quite interesting. A more unstable (less stable) money demand would normally call for some change in the operating procedures of monetary policy, especially when the shocks are of a "permanent" (regime-specific) nature and when those procedures entail some type of targeting of monetary aggregates. According to the above evidence, however, Mexico's monetary policy--(crudely) proxied by the behavior of TF--does not seem to have changed significantly after the country adopted a floating exchange rate regime in 1995. In principle, this would tend to undermine the effectiveness of monetary policy, in particular its ability to achieve the desired combination of inflation/output outcomes, and may be contributing to explain the (slight) anomalies in the behavior of the peso/dollar rate discussed earlier in this section. The finding could also be taken as evidence that the BOM has continued to take into account the

\footnotetext{
${ }^{30}$ For space considerations, these results are not reported in table 5. They are available upon request.
} 
behavior of the exchange rate for conducting monetary policy after the December 1994 devaluation. We explore this issue in greater detail in the section below.

\section{What does the Bank of Mexico really do?}

The peso devaluation of December 1994 gave a severe blow to BOM's credibility. The damage became acutely apparent in the first quarter of 1995, when uncertainties about Mexico's capacity to redeem in full its large stock of short-term debt and about its authorities' resolve to confront the crisis led to an enormous depreciation of the peso that rendered obsolete the monetary program that had been announced by the BOM in mid-January. A critical turning point took place in March-April, following the securing of the US\$ 52 billion international support package arranged by the IMF and the U.S. Treasury and the authorities' announcement of a revised (and more realistic) set of macroeconomic policies and targets for 1995. The draconian tightening of monetary policy that accompanied these developments--with Cetes interest rates remaining above 70 percent for several weeks--put an end to the free fall of the peso, and gradually restored calm to financial markets.

From then on, BOM confronted the arduous task of restoring its tarnished credibility. To this effect, it reiterated publicly and repeatedly that the primary objective of its monetary policy was to arrest the inflationary effects of the peso depreciation and to rapidly bring down inflation to moderate levels, that the exchange rate and interest rates would be freely determined by market forces, and that they would refrain from imposing any type of control or restriction to capital movements. The BOM also made it clear that other (secondary) objectives of its monetary policy were to prevent "excessive" fluctuations in the value of the peso, to rebuild its stock of international reserves, and to provide limited (and mainly technical) assistance in the 
restructuring of the badly damaged banking system. To underscore their resolve to increase the transparency of their actions and policies, the BOM made available to market analysts and the public at large timely information on its balance sheet and other monetary and financial indicators, and stepped-up its efforts to disseminate and explain the (various) initiatives that were being adopted to deal with the unfolding crisis in the banking system.

Financial analysts and other observers of the Mexican economy gave a lukewarm reception to these bold initiatives and, throughout 1995 , raised repeated objections to BOM's monetary policy. Some criticized the (revised) annual inflation target of 42 percent--on the grounds of being either unambitious or unattainable. Others questioned the overall policy framework, in particular BOM's decision to adopt--and its intentions to abide by the rules of--a floating exchange rate. The arguments offered in support of these criticisms were quite unwieldy. The most sophisticated observers based their assessment of the stance (and likely consequences) of BOM's monetary policy on mechanical applications of the quantity theory of money, variants of interest rate parity conditions and/or simple PPP-based calculations. Others, a vast majority, based their assessment on anecdotal evidence, personal intuition and non-economic considerations.

Sometime in 1996 the tenor of the critiques to Mexico's monetary policy started to change. The (many) worst-case scenarios advanced in 1995 were shelved one after another in light of a number of favorable developments including a steady fall in the rate of inflation ${ }^{31}$, signs of an early rebound of output growth, the turnaround of the external current account balance, the repayment in full of the stock of Tesobonos, and Mexico's successful re-entry to

${ }^{31}$ The monthly rate of CPI inflation peaked at 8 percent in April 1995, averaged 2.5 percent from June 1995 to April 1996 and stayed below 2 percent from May to November 1996. The 12-month rate of inflation peaked at 52 percent in December 1995 and fell steadily thereafter. 
international capital markets. ${ }^{32}$ At this point, a more constructive debate about the actual priorities and operating procedures of BOM's monetary policy took center stage. In particular, as noted in Section III, a number of analysts started to argue that the BOM was gearing its monetary policy, through changes in short-term interest rates, to maintaining an artificially strong peso. Underlying this view was the observation that, since mid-1995, periods of relative nominal exchange rate stability and falling interest rates had been interrupted by episodes of exchange rate depreciation and interest rate rises that had been quickly reversed and, hence, had not served to arrest the real appreciation of the peso. See Figure $5 .^{33}$

The BOM has systematically dismissed these arguments, considering them misguided and unfounded. Specifically, the BOM has maintained the position that its monetary policy is not geared at attaining or maintaining any particular level of the exchange rate or of interest rates; that these variables are freely determined by market forces; and that its monetary policy actions are solely guided by the dual objectives of securing its annual inflation target and ensuring an orderly functioning of the money and foreign exchange markets (Gil-Diaz 1997). But the debate on what the BOM really does has continued; JP Morgan's Emerging Markets Data Watch of October 3, 1997 (page 6) noted that: "It has often been argued in the past year or two that Banxico has been exacerbating upward pressure on the peso by tightening monetary policy," and David Malpass, chief economist of Bear Stearns, stated in the Wall Street Journal that: "Mexico stopped its economic and financial deterioration almost overnight [in the aftermath of the 1994

\footnotetext{
32 On Mexico's external debt strategy following the 1994 crisis see Andrews and Ishii (1995) and IMF (1996). For an overview of the main macroeconomic developments in Mexico in 1995 and early 1996 see OECD (1996).

${ }^{33}$ The figure shows that from late 1995 to September 1997 it is possible to visually identify at least six episodes or cycles of "spikes" in the nominal exchange rate and interest rates followed by relatively long periods of exchange rate stability and falling interest rates; the approximate starting date of these episodes (i.e., the "spikes') were: OctoberNovember 1995, February-March 1996, June-July 1996, October 1996, March 1997 and June 1997. The figure also shows that, over time, the spikes have become smaller in size, and there has been some upward ratcheting of the nominal exchange rate as well as a clear downward trend of nominal interest rates.
} 
devaluation] by announcing a feedback mechanism between the exchange rate ... and ... monetary liquidity ...."34

Central banks often act in ways that do not exactly correspond to their pronouncements. Notwithstanding the emphasis that the recent literature on central banking places on the transparency dimension of monetary policy ${ }^{35}$, there is nothing intrinsically wrong or unusual with that type of behavior. In fact, a number of analysts have used statistical methods to shed light on the systematic component of central banks' actions that is not reflected in their public pronouncements in order to obtain a better understanding of what is it that central banks really do. Taylor's (1993) analysis of the Fed's behavior since the 1960 s is, perhaps, the best known example of this approach. More recently, Clarida and Gertler (1997) tried to infer from the data the way in which the German Bundesbank conducts monetary policy, and found that, in practice, the actual conduct of this policy differed significantly from the official line ${ }^{36}$. The empirical analysis of Mexico's monetary policy that we undertake in the last part of this section follows a similar line of inquiry.

We acknowledge at the outset that, given Mexico's very limited experience with a floating exchange rate regime (merely three years), the task of identifying what BOM really does is extremely difficult. In fact, those that have undertaken this type of challenge for advanced countries with at least twenty-five years of data have found it to be a very "complex issue, one that...[their] analysis cannot fully resolve" (Clarida and Gertler 1997, page 364). A particularly important limitation of our analysis is that it lacks an explicit macro-model of the transmission

\footnotetext{
34 "Free Float to Disaster," The Wall Street Journal, October 20, 1997, page A23. (1997).

${ }^{35}$ See, for example, the discussion in Federal Reserve Bank of Kansas City (1996) and Romer and Romer

${ }^{36}$ Bernanke and Mihov (1997) reached a similar conclusion using (slightly) different VAR techniques. The Bundesbank's official view on monetary policy, however, has remained the same (see Issing (1997)).
} 
mechanism of monetary policy, or of inflation determination, in Mexico under a floating exchange rate. ${ }^{37}$ For these reasons our results have to be considered as preliminary and only suggestive. Moreover, since we recognize the problems involved in trying to unearth the systematic component of central bank behavior from "noisy" high-frequency data, we have avoided the use of overly ambitious econometrics, settling instead for a more mundane--but we believe useful--and eclectic approach that combines diagrammatic analyses with basic time series techniques. The rest of the section is divided in two parts: sub-section IV.1 describes and discusses briefly the way in which the BOM says it conducts monetary policy; sub-section IV.2 presents the results of our empirical investigation. A key question that we address is whether (and to what extent) the BOM has used some type of exchange rate-based feedback rule to conduct its short-run monetary policy.

IV.1 BOM's Monetary Policy: The Official View

At a very general level, BOM's approach to monetary policy seems quite standard and straightforward. Abiding to its constitutional mandate to maintain price stability, at the end of every year the BOM--in conjunction with the rest of the economic team--chooses and announces an end-point inflation target for the following calendar year ${ }^{38}$ and specifies a time path for the demand for money consistent with that inflation target and with the expected evolution of output, interest rates and other macro-variables. Based on a number of considerations, including its relative stability over long periods of time, the monetary aggregate preferred by the BOM is the monetary base ${ }^{39} \mathrm{BOM}$ 's conduct of monetary policy throughout the year is therefore geared

\footnotetext{
${ }^{37}$ For empirical analyses of the transmission mechanism of monetary policy and inflation in Mexico prior to the 1994 devaluation see Copelman and Werner (1997) and Galindo (1997). See also Kamin and Rogers (1997).

${ }^{38}$ The announcement usually takes place in the context of the presentation to Congress of the economic program for the following year, which is spelled out in a document called "Criterios Generales de Política Económica."

${ }^{39}$ Since the adoption of a system of zero reserve requirements on deposits in the early 1990s, Mexico's monetary base is approximately equal to the amount of currency in circulation.
} 
primarily at keeping the intermediate target (the monetary base) on (close to) its pre-specified path, taking due account of new (unexpected) developments in the economy. Seen in this way, BOM's approach to monetary policy resembles a conventional two-stage intermediate target procedure, which, given BOM's revealed preference for the monetary base, can be thought of as a "base money targeting framework."

At a more detailed level, however, BOM's conduct of monetary policy looks somewhat less conventional. This is so for two main reasons. First, the BOM combines its annual estimates of the demand for monetary base and (historical) information on seasonal fluctuations in that monetary aggregate to produce quarterly, monthly and daily estimates of the demand for base money. And second, unlike the majority of central banks, the BOM does not use short-term interest rates as an operating target to guide its daily operations and/or modify the stance of monetary policy. Instead, since 1995 , the BOM uses a system of cumulative balances with commercial banks (also known as reserve averaging around zero) to guide its daily supply of liquidity to the economy. It is through changes in the BOM's objective for the system's cumulative balance that the monetary authority conveys signals (to banks) about its desired stance of monetary policy (see O’Dogherty (1997)).

Strict adherence to this short-term operating procedure implies that, in "normal" times (days), BOM's monetary policy consists mainly of accommodating or satisfying all the liquidity (currency) demanded by the banks provided that they are in compliance with the existing objective for the system's cumulative balance. ${ }^{40}$ In those times, BOM actions arguably do not exert a major influence on (nor are influenced by) the exchange rate or interest rates; all

\footnotetext{
${ }^{40}$ The actual measurement of compliance is a rather complicated process that depends crucially on the period over which the cumulative balances are computed (the maintenance period) and the net position of individual banks visa-vis the BOM. See Aguilar and Juan-Ramón (1997) and O'Dogherty (1997).
} 
movements in these variables are, in principle, market-determined outcomes (Gil-Díaz (1997)). According to the official view, the role of the daily estimates of the demand for monetary base in these "normal" times is rather limited. Those estimates provide a benchmark against which BOM officials can compare the amount of liquidity demanded by the banks on a given day or week, but not much else. The daily assessment of monetary conditions by the BOM board, the argument goes, takes precedence over the (inherently inaccurate) estimates of daily money demand when deciding on the amount of liquidity the BOM will inject to the system. A key premise behind this course of action is, clearly, that the banks' daily demand for liquidity reflects (or provides a better estimate of the "true" demand for monetary base which the BOM has to satisfy to ensure an orderly functioning of the money market.

As noted above, however, the operating procedure leaves scope for the BOM to conduct a more "active" monetary policy if it so wishes. Concretely, if, for whatever reason, the BOM decides at a given point in time that market conditions require or justify a change in the stance of its monetary policy, the BOM can "signal" that decision to the market (more precisely, to the banks) by changing its objective for the system's cumulative balance. Specifically, BOM officials argue that they can and will announce (and thereafter enforce) a lower objective for the system's cumulative balance if they want to tighten the stance of monetary policy, and a higher objective if they want to ease monetary conditions. According to their view, these "signals"--and the ensuing enforcement of the new objectives for the cumulative balance--will alter the shortrun behavior of banks and, through their actions, market interest rates in the desired direction-i.e., interest rates will rise when the BOM tightens its stance, and will fall in the opposite case. These policy-induced changes in market interest rates will, in due course, affect the demand for 
monetary base also in the desired direction, thus contributing to eliminate the (perceived) disequilibrium in the money market (Gil-Díaz (1997)).

We will refrain from assessing the analytical consistency of BOM's view of monetary policy as described, for example, in the articles cited above. We leave that (daunting) task for another occasion. We will say, however, that we find it most peculiar that the BOM seems more comfortable casting the discussion of its monetary policy over (extremely) short horizons than over the longer term (say, six months or a year). All central banks conduct day-to-day operations in a number of markets using a variety of (direct and indirect) instruments. Few of them feel compelled to describe the nitty-gritty of their daily operating procedures when asked to characterize their framework for monetary policy. There are many good reasons for this, but, in our view, none more important than the long and variable lags that are normally thought to undermine the short-run effectiveness of monetary policy. BOM's view of monetary policy as equivalent to daily liquidity management turns this old argument on its head. We are also puzzled by the small number of episodes in which the BOM acknowledges having modified the stance of its monetary policy, and therefore influenced the short-run behavior of interest rates and the exchange rate, in response to market developments. By its own reckoning, the BOM changed the stance of monetary policy 15 times between September 25 and December 25, 1995, 8 times between December 1995 and November 1996, and kept the stance unchanged (at a "neutral" level--i.e., a cumulative balance of zero) during the first three quarters of 1997 (Gil-Díaz (1997); Aguilar and Juan-Ramón (1997) ). It follows from this that, according to the BOM, all movements of interest rates and the exchange rate in, say, the first semester of 1997 (or in any other long period in between changes in the BOM's objective for the system's cumulative 
balance) did not justify nor elicit a response of monetary policy. This type of implication merits, at least, a closer look at the data. We took on the challenge .

\section{IV.2 What does BOM Really do? An Exploratory Investigation}

In this sub-section we use daily and weekly data to better understand the way in which BOM has conducted monetary policy in the post crisis period. Our analysis relies on high frequency data for two reasons: first, the short period of time elapsed since the adoption of the floating system, leaves us with no alternative but to use every data point available; second, and as discussed in the preceding sub-section, BOM has explicitly stated that, at least since 1996, it has aimed at satisfying the demand for monetary base on a daily basis. Although, due to data availability, most of the statistical analysis concentrates on 1996-1997, we also present a brief discussion of episodes of large day-to-day exchange rate changes during 1995-97. The subsection is organized as follows: we start by analyzing briefly the evolution of the daily target for the monetary base and comparing its behavior to that of the actual monetary base. This analysis shows that, especially during 1997 , there have been important deviations between target and actual base money. We then analyze the time series properties of a number of daily series, including the monetary base, Cetes interest rates and the spot exchange rate, among others. Our next step is to examine the behavior of these key variables in the periods surrounding 30 large daily peso depreciations. We then proceed to estimate a series of simple trivariate VARs using weekly data. We end up by presenting some estimates of a weekly monetary policy reaction function. Both the VAR and the reaction function analyses provide some evidence in support of the view that BOM has taken exchange rate developments into account to conduct monetary policy. 
Figure 6 presents daily data on the evolution of target and actual monetary base (in billions of pesos) during 1996-1997. The figure shows that between January 1996 (the first date for which we have BOM estimates of the daily demand for monetary base) and end-January 1997 the deviations between these two variables were rather small. Starting in February 1997, however, the actual monetary base persistently exceeds the estimated (target) base--the median daily deviation for this period was significantly higher than for the January 1996-January 1997 period. BOM has explained these discrepancies by arguing that during most of 1997 the rate of remonetization had been stronger than anticipated, and that in estimating the demand for money it had missed important seasonal variations, including the surge in the demand for cash during mother day's weekend and the faster than expected rate of growth of GDP during that year. ${ }^{41}$ Figure 7 presents the proportional deviations between actual and target base--a variable we have called "excess liquidity." The top panel (panel A) displays the actual deviations between actual and target base, while panel B presents a detrended excess liquidity index. Both figures, however, tell a similar story: throughout the period under analysis, these excess liquidity indices exhibited significant variability. An important question is whether these deviations from the daily targets for monetary base (released to the public in late 1996 in an effort to facilitate their understanding of BOM's monetary policy) were the result of deliberate policy responses to developments deemed undesirable by the BOM--including exchange rate changes--or whether they represent a combination of noise and of BOM's stated policy of simply accommodating the banks' actual demand for liquidity on a daily basis. The analysis below addresses precisely this question.

4 "On reactions to the overshooting of the base money target in early 1997 see, for example, The Wall Street Journal's “Mexico Central Bank Primes Economy; Critics See Attempt to Sway Elections", May 27, 1997. See, also a related story published by the New York Times on May 29, 1997. 
Table 6 presents Augmented Dickey-Fuller (ADF) tests for weekly data on interest rates (28-day Cetes), the rate of depreciation of the peso vis-a-vis the US dollar, the log of the monetary base, our measure of excess liquidity (non-detrended), and the yield on U.S. 30-years treasury bonds. As can be seen, only the rate of depreciation and excess liquidity are stationary in levels. All other series are stationary in first differences. Table 7 presents $P$-values for Granger "causality" tests for the variables of interest for 1996-97, as well as for two sub-samples corresponding to each calendar year. For most of the series the P-values are rather high and, thus, it is not possible to reject either of the two "causality" hypotheses. There are, however, two important exceptions to this result. First, for the complete sample the null hypothesis that depreciations do not cause excess liquidity is rejected at conventional levels. Second, the null hypothesis that peso depreciation does not cause interest rates is rejected for the first sub-sample, as is the hypothesis that the base does not cause peso depreciation during 1997. Given the short period considered and the high frequency of the data, however, these results should be interpreted with caution. In fact, as pointed out already, this caveat applies to all the results reported in this sub-section.

Table 8 contains data on the behavior of a number of key variables in the days surrounding 30 large daily depreciations of the peso/dollar rate since the adoption of the floating regime. The first 10 episodes correspond to the ten largest peso depreciations of 1995 , while the other 20 consist of the largest depreciations observed during $1996-1997 .^{42}$ Column $\mathrm{A}$ is the episode's date; column B contains data on the change (in basis points) in the 28-day Cetes interest rate in the secondary market one day after the depreciation episode relative to one day

42 This allowed us to have episodes from all three years. Since the exchange rate was significantly more volatile in 1995 (see section III), had we chosen the 30 largest depreciation for the three-year period taken as a whole we would have ended up mostly with 1995 episodes. 
prior to the depreciation; column D contains the change in the Cetes primary interest rate in the period spanning from the Cetes auction prior to the depreciation to the first auction after the depreciation; column E presents the change in the monetary base that had been programmed (estimated) to take place in the period spreading from the day prior to the depreciation to five days after the depreciation; column $\mathrm{F}$ is the actual change in the monetary base during the same period; and, finally, column $\mathrm{G}$ presents the change in the detrended liquidity index in the five days following the depreciation. ${ }^{43}$

Several interesting facts emerge from this table. First, in 22 of the 30 episodes there is an increase in the auction-to-auction primary Cetes interest rates. Second, and highly related, in 26 of the 30 episodes the secondary market Cetes interest rate rises in the day following the depreciation. A possible explanation for these results--and one that we explore in greater detail below-- is that BOM reacts to (relatively) large losses in the value of the peso by tightening liquidity relative to its daily target and, thus, putting upward pressure on interest rates. The BOM has acknowledged that it indeed tightened liquidity in the period following some -- but not all--of these depreciation episodes. For example, on November 9, 1995 the BOM lowered significantly its objective for the system's cumulative balance. A similar measure was taken in January 23 and 25, 1996 (Aguilar and Juan-Ramón (1997)). Interestingly enough, however, BOM has denied that it has systematically tightened liquidity in response to large peso depreciations, as it has denied having defended or targeted any particular level of the peso/dollar rate. Moreover, as noted before, according to official pronouncements, there has been no change in the stance of monetary policy (exchange rate-motivated or not) since October 1996. BOM's (semi) official

43 As may be seen, the data on the 1995 episodes are restricted to exchange rate and Cetes interest rate movements. Data on BOM's daily estimates of the monetary base for 1995 (if they exist) were not available to us. 
explanation for the apparently systematic relationship between peso depreciations and interest rate rises captured in Table 8 is that the increases in (Cetes) interest rates are market-determined outcomes; concretely they are simply a reflection of interest arbitrage conditions. A problem with this explanation, is that it requires that the public's expectations of peso depreciation exhibit some degree of persistence; the analysis of (actual) daily depreciations, however, suggests strongly that they have been white noise in 1996-1997.

Columns $\mathrm{E}, \mathrm{F}$ and $\mathrm{G}$ in table 8 are intended to shed some light on monetary policy in the periods surrounding large peso depreciations. We are particularly interested in comparing the actual monetary stance taken by BOM in the days following these depreciations, with the policy that had been programmed before the jump in the exchange rate took place. We compared the cumulative targeted and cumulative actual increase in the monetary base five, ten and fifteen days following the depreciation episode. In all cases we found that in one half of the episodes the actual growth in the monetary base fell short of its programmed rate of growth, while in the other half of the cases liquidity creation exceeded the target. Columns $\mathrm{E}$ and $\mathrm{F}$ present the figures corresponding to five-days cumulative changes in the monetary base. Interestingly enough, these figures suggest an important change in behavior in late September 1997, when the BOM announced that it would be willing to adopt a more "relaxed" monetary stance. As may be seen, between January 1996 and August 1997--a period that can be characterized as more "conservative"--monetary policy was tighter than programmed in eight of the twelve episodes.

In order to gain further insights into the conduct of monetary policy in Mexico we estimated two small scale VAR systems using weekly data for January 1996-October 1997. Although, as noted earlier, we make no attempt at estimating a full-fledged model of the macroeconomic transmission mechanism in Mexico, we implicitly assume that the following 
process is at work: changes in liquidity (the monetary base) engineered by BOM affect short term interest rates (28-day Cetes) in the secondary market and the public's expectations.

Changes in interest rates, in turn, impact on the peso/dollar rate. Interest rate changes, jointly with changes in exchange rates will, in due course, affect aggregate expenditure and inflation. ${ }^{44}$ Our main interest in estimating alternative VAR specifications is to ascertain the extent to which there has been some type of feedback from key macroeconomic variables--in particular exchange rates and interest rates--to monetary policy. The analysis is based on the estimation of two trivariate VARs. In the first one--which we call VAR1--we used a measure of "excess liquidity" (defined as the log difference between actual and target monetary base) as a proxy for BOM's monetary policy; in the second (VAR2) we used weekly changes in the log of the monetary base as the policy proxy. In both VARs the two other endogenous variables were the 28-day Cetes interest rate and the weekly rate of change in the peso/dollar rate..$^{45}$ In addition the VARs included the following exogenous variables: the yield on the U.S. 30-year treasury bond lagged one period, a time trend, the change in the log of the target monetary base, and a dummy variable that took the value of one for (weekly) depreciations of the peso and zero otherwise. ${ }^{46}$ Additionally, in VAR2 (which uses the actual change in monetary base as the measure of monetary policy), we added the lagged deviation between the actual and target monetary base as an exogenous variable. Existing empirical evidence for a large number of countries strongly suggests that the monetary transmission mechanism is characterized by fairly long and variable

44 This resembles the transmission mechanism arguably assumed by the BOM when analyzing monetary policy. See, for example, O’Dogherty (1997).

${ }^{45}$ As will be explained later, the focus on the monetary base, as opposed to short-term interest rates, distinguishes this study from other attempts at estimating policy responses of central banks to specific shocks.

46 When this dummy was excluded the results were essentially the same for VAR1, and changed slightly for VAR2. In the results reported here we introduced the Cetes rate in levels. If, however, it is incorporated in first differences the results are not affected significantly. Whether variables should be differenced in VAR analysis is still an unresolved issue in time series analysis. See, for example, Enders (1995). 
lags. This presents a significant problem for analyses like ours that rely on high frequency data for a relatively short period of time. Indeed, if a long and unrestricted lag structure is used we are bound to run into a serious degrees-of-freedom problem. For this reason in this paper we considered a series of restricted lag structures. After some experimentation, and in order to maintain some degree of parsimony, we settled for a structure that included lags 1 through 3 , plus lags 5 and 8. When a long unrestricted structure (say, twelve lags) was used, the results were very similar but the loss of degrees of freedom was significant.

Figures $8 \mathrm{~A}$ and $8 \mathrm{~B}$ present the impulse response functions for the two estimated VARs. ${ }^{47}$ The following insights may be obtained from these results. First, in both cases a one standard deviation shock to the weekly rate of depreciation seems to generate a tightening in monetary policy. This appears to be the case independently of whether we consider excess liquidity, or the change in the base as the measure of the policy stance. Interestingly enough, the impulse response functions from both VARs suggests that, following an exchange rate shock, BOM restricts liquidity for a period of approximately five weeks. Both figures also suggest that liquidity is eased (very) slightly in response to a domestic interest rates shock, and that Cetes interest rates rise as a consequence of a shock to the rate of depreciation. The most important difference between these two VAR estimates consists of the response of the rate of depreciation to a one standard deviation shock to the Cetes interest rate (the bottom panel of each figure). The impulse response function obtained from VAR1 (Figure 8A) suggests that the rate of depreciation declines immediately following a shock to domestic interest rates. According to VAR2, however, a shock to domestic interest rates generates a small short-lived increase in the

47 Naturally, in performing this analysis we were careful to consider alternative orderings of the three endogenous variables incorporated in our VARs. We found out that the orderings did not affect the results in any significant way. 
the rate of depreciation, which starts declining only during the second week. In both cases, however, it takes about 8 weeks for the effect of the interest rate shock to disappear. Broadly speaking, then, the results obtained from our unrestricted VAR estimations provide some preliminary evidence suggesting that BOM has adjusted its monetary policy in response to changes in (some) macroeconomic conditions. Concretely, these results suggest that, at least between January 1996 and October 1997, liquidity was tightened when there was an unexpected increase in the rate of peso depreciation. In principle, we could interpret these results as suggestive of the existence of some type of "policy reaction function" of the BOM, somewhat similar to those that have been postulated and identified for other central banks--including the Federal Reserve and the Bundesbank. To the extent that--as BOM has explicitly stated-inflation control is the primary objective of Mexico's monetary policy, and peso depreciations are associated with higher inflation (at least at low frequencies), it seems reasonable to conjecture that the monetary authorities will not be indifferent to large declines in the value of the peso, even in the short run.

The results reported above are subject to some limitations, including the fact that (due to lack of data) some important variables--most notably, inflation and real activity--- were omitted, and that a somewhat restricted lag structure had to be used. Furthermore, these results are subject to the well-known limitations of VAR analyses. In order to provide additional structure to the discussion, and to explore further the way in which monetary policy has responded (if at all) to developments in the foreign exchange market, we estimated a number of reaction functions for the BOM for the period $1996-1997 .^{48}$ In this analysis, however, we try to go a step

\footnotetext{
${ }^{48}$ As we argued earlier, and as has been noted by several researchers, this is not an easy task. In our case the well-known difficulties associated with estimating and analyzing reaction functions are compounded by the fact that we had no option but to use high frequency data.
} 
further than in the VARs, and we try to be more specific on the nature of the exchange rate feedback rule. In principle, central banks can take into account two type of exchange rate-related developments when conducting monetary policy; first, they may react to changes in the exchange rate over a given horizon, tightening liquidity in response to (large) depreciations, and expanding it after (large) appreciations. In an open economy this type of monetary policy is consistent-- at least in the medium term--with a central bank that tries to attain a given inflation objective. Second, the central bank may have a target for the level of the (nominal) exchange rate. Under a (dirty) float this target will usually be rather "soft," and may even change over time. In this case the monetary authorities will intervene by tightening liquidity when the exchange rate approaches (or exceeds) the target, and will (may) ease the stance when the exchange rate falls below the target. ${ }^{49}$ In the analysis presented below we make an effort to distinguish between these two types of exchange rate-related feedback rules. In particular, using weekly data for Mexico in 1996-97, we investigate whether the BOM's behavior can be characterized by any of the following three alternative reaction functions for monetary policy:

(A) A simple exchange rate change reaction function: In this case the central bank reacts by tightening monetary policy whenever the exchange rate depreciates by more than a certain rate $\left(\Delta \log S^{*}\right)$, and by easing the monetary stance if the currency depreciates by less than that rate. In that sense, then, this is a symmetric reaction function. Formally, the function can be written as:

$$
\begin{aligned}
& \Delta \log \text { Base }_{\mathrm{t}}=\Delta \log \text { Target }_{\mathrm{t}}-\alpha\left(\log \text { Base }_{\mathrm{t}-\mathrm{i}}-\log \text { Target }_{\mathrm{t}-\mathrm{l}}\right) \\
& -\Sigma \beta_{\mathrm{j}}\left(\Delta \log \mathrm{S}_{\mathrm{t}-\mathrm{j}}-\Delta \log \mathrm{S}_{\mathrm{t}-\mathrm{j}}\right)+\Sigma \gamma_{\mathrm{j}} \Delta \mathrm{x}_{\mathrm{t}-\mathrm{j}}+\epsilon_{\mathrm{t}}
\end{aligned}
$$

\footnotetext{
${ }^{49}$ Of course, this type of policy response resembles that required by a band-system with (soft) bands.
} 
where $\left(\log\right.$ Base $_{t-1}-\log$ Target $\left._{t-1}\right)$ is the stock disequilibrium between the observed and target monetary base in period $t-1 ; \Delta \log S_{t-j}$ is the rate of change in the spot exchange rate $(S)$ in period $t-j ; \Delta \log S^{*}{ }_{t-j}$ is the target (tolerable) change of $S$ in that period; $x$ is a vector of other variables that may influence the central bank's monetary policy stance, such as the international (U.S.) interest rate and domestic (Cetes) interest rates; and $\epsilon_{\mathrm{t}}$ is an error term with the usual properties. Since the coefficient of the target base growth ( $\Delta \log$ Target $v$ is, in theory, equal to one, equation (7a) can be interpreted as capturing deviations of actual from targeted growth in the monetary base. The monetary base will grow at a lower-than-programmed rate if there is an accumulated stock disequilibrium (i.e., if $\left(\log\right.$ Base $_{t-1}-\log$ Target $\left._{t-1}\right)>0$ ), and if the rate of depreciation exceeds its target.

Equation (7a) captures some important peculiarities of the Mexican case, and differs in a number of ways from reaction functions estimated by authors that have investigated the behavior of other central banks. First, our measure of the monetary "instrument" is the monetary base rather than a short-term interest rate. This is because, as noted before, the BOM has stated explicitly that it does not use interest rates as an instrument nor does it "manipulate" them in any systematic way. Second, and in line with (some of) BOM's pronouncements, we interpret BOM's monetary policy framework as one of "base money targeting" that operates through daily injections of liquidity. And third, as noted already, due to the lack of data at the weekly frequency, we were unable to include deviations of inflation and of indicators of real activity from their target. As Clarida and Gertler (1997) and others, however, we control for lagged effects of the independent variables on the monetary policy stance.

(B) A large-depreciations reaction function: In this case the central bank only reacts to large depreciations. If the spot exchange rate depreciates by more than a certain rate, the 
monetary authorities tighten money creation below its pre-established target; otherwise, an effort is made to keep base money on its programmed path. Formally, this type of reaction function is captured by:

$$
\begin{aligned}
& \Delta \log \text { Base }_{\mathrm{t}}=\Delta \log \text { Target }_{\mathrm{t}}-\alpha\left(\log \text { Base }_{\mathrm{t}-1}-\log \text { Target }_{\mathrm{t}-1}\right) \\
& -\Sigma \beta_{\mathrm{j}}\left(\text { Dep }_{\mathrm{t} \cdot \mathrm{j}}\right)+\Sigma \gamma_{\mathrm{j}} \Delta \mathrm{x}_{\mathrm{t} \cdot \mathrm{j}}+\epsilon_{\mathrm{t}},
\end{aligned}
$$

where Dep ${ }_{t-j}$ is equal to the actual rate of depreciation when a certain threshold (Dep*) has been exceeded, and zero otherwise. In that regard, then, equation (7b) implies that the central bank behaves asymmetrically; monetary policy only departs from its targeted path if there are "bad news" on the exchange rate front. In a context of declining inflation, as Mexico in 1996-1997, we would expect that the rate of depreciation that will trigger this type of response (Dep*) would fall over time.

(C) An exchange rate level reaction function: In this case the policy is characterized by an undeclared (and unknown to the public) maximum value of the (spot) exchange rate that the authorities are willing to tolerate. The monetary authorities will attempt to "defend" this level by tightening liquidity when the actual rate approaches this threshold. There are a number of important differences between this type of response and a formal system of exchange rate bands. First, in this case there is only a ceiling, and not a floor for the exchange rate; second the ceiling tends to be "soft", in the sense that it can be abandoned -- arguably, without major reputational costs -- if the circumstances so require; and third, contrary to a formal bands system, central bank "intervention" does not have to take the form of sales or purchases of foreign exchange reserves. Formally, this reaction function can be expressed as:

$$
\begin{aligned}
& \Delta \log \text { Base }_{t}=\Delta \log \text { Target }_{\mathrm{t}}-\alpha\left(\log \text { Base }_{\mathrm{t}-1}-\log \text { Target }_{\mathrm{t}-\mathrm{l}}\right) \\
& -\Sigma \beta_{\mathrm{j}}\left(\text { Int }_{\mathrm{t}-\mathrm{j}}\right)+\Sigma \gamma_{\mathrm{j}} \Delta \mathrm{x}_{\mathrm{t} \cdot \mathrm{j}}+\epsilon_{\mathrm{t}},
\end{aligned}
$$


where Int is an intervention indicator. The value of this indicator is zero if the actual spot rate is below the "intervention threshold", and is equal to the difference between the spot and the "threshold" once the latter is crossed. A difficulty with estimating an equation like (7c) is that central banks in general, and BOM in particular, do not make public (or even acknowledge the existence of) an "intervention threshold" for the exchange rate or any other "information variable". For this reason, we decided to experiment with several alternative threshold values of Int.

In order to estimate equations ( $7 \mathrm{a}-7 \mathrm{c})$ it is necessary to make concrete assumptions about $\Delta \log \mathrm{S}^{*}$, Dep* and Int. We took our cue from the annual inflation targets announced by the Mexican authorities. Specifically, we assumed that, starting in mid 1995, the BOM expected that the peso/dollar rate would depreciate at a declining rate; concretely, we assumed that $\Delta \log \mathrm{S}_{\mathrm{t}}{ }_{\mathrm{t}}=$ $\lambda-\rho$ time $+\Phi$ time $^{2}+\mu_{1}$, where $\mu$ is an error term. This means that equation (7a) will include as regressors the actual weekly rate of depreciation, plus a time and time-squared terms. Regarding equations ( $7 b$ ) and (7c) we considered a series of alternative policy rules. In doing so, we tried to restrict the number of weeks in which the authorities adjusted the monetary stance to no more than 25 percent of the total weeks in our sample. With respect to ( $7 \mathrm{~b})$, in the estimations reported in tables 9 and 10, we assumed that Dep was equal to the actual (weekly) rate of depreciation if this rate exceeded 0.6 percent in 1996, and 0.35 percent in 1997. In all other weeks, Dep was set equal to zero. For equation (7c), the results reported below were obtained under the assumption that the threshold for the exchange rate level was 7.6 pesos/dollar in 1996 and 7.85 in 1997. Whenever the spot exchange rate exceeded these thresholds, Int was set equal to the difference between the actual spot rate and the threshold; it was zero otherwise. In order 
to check for the robustness of the results we considered a number of alternative rules (available upon request), the results reported below were largely unaffected.

Table 9 presents the results obtained from an OLS estimation of equations ( $7 \mathrm{a}-7 \mathrm{c})$. With the exception of $\Delta \log$ Target $_{t}$, all the regressors in the equations were included with a lag of one period (week). Table 10 presents the result from an Instrumental Variables estimation. In this case we allowed for contemporaneous values of $\Delta \log$ S, Dep and Int. In both sets of regressions we used polynomial distributed lags (see tables for details); based on the VAR results discussed above we allowed for up to eight lags in the depreciation and domestic interest rate regressors. As can be seen, the results are broadly supportive of the view that the BOM has followed a base money targeting approach with feedback from the exchange rate in 1996-97. In every equation the coefficient of the target base growth is not significantly different from one, and has a very large t-statistic. An F test suggests, however, that this is not the only variable driving the results in these regressions; the other regressors, as a group, are significantly different from zero in all the equations. The coefficient of the stock disequilibrium is, as expected, negative. Its point estimate, between -0.42 and -0.28 , suggests that BOM has, by and large, made efforts to correct rather rapidly discrepancies between target and actual monetary base. The coefficient of changes in the Cetes and US interest rates are negative but not significant in any of the regressions, and were subsequently dropped from the analysis. More important for our purposes is the finding that in all equations the sum of the coefficients of the exchange rate-related variables is significantly negative. This suggests that, as conjectured, the BOM has systematically adjusted its monetary policy in response to exchange rate developments.

As pointed out above, an important question refers to whether BOM has focused on exchange rate changes or levels when modifying its monetary stance. We addressed this issue in 
equations (7.6) and (7.11) where we included, in the same equation, both Dep and Int as regressors. As may be seen, when this is done, the coefficients of Int --the exchange rate levels feedback indicator--is, in both cases, statistically insignificant, while that of Dep continues to be significantly negative. Hence, this provides some evidence in support of the view that BOM has adjusted its monetary policy in response to exchange rate changes, without attempting to attain or maintain a particular level of the exchange rate. Furthermore, according to the results of equation (7.7) BOM seems to have followed an asymmetric feedback rule, responding only to large peso depreciations. An important question is whether the feedback rule has been stable through time. In order to ascertain whether this was the case we used a calendar-year dummy variable to analyze the stability of the coefficients of the exchange rate regressor. The results tend to suggest that the relative importance of the feedback rule increased during 1997 (the year where BOM allegedly maintained a neutral stance of monetary policy). For example, in equation (7.6) the sum of the coefficients of DEV is -0.801 for 1996 and -2.123 for 1997 .

To sum up, in this section we have used high-frequency data to ascertain whether BOM's monetary policy has contributed to the relative stability exhibited by the peso/US dollar rate during (most of) 1996 and 1997. The results obtained --based on episodic analysis of key variables, the estimation a two VAR systems, and of monetary policy reaction functions -provide some evidence in support of the view that during this period BOM indeed modified its monetary stance in response to exchange rate developments. Specifically, our analysis tends to suggest that during 1996-97 Mexican monetary authorities tightened monetary policy in response to large depreciations of the peso. There is no evidence, however, indicating that BOM aimed at attaining or maintaining a specific level for the peso/dollar exchange rate. A final, though by now familiar, qualification is in order: the short period elapsed since Mexico adopted a floating 
exchange rate and the lack of data for some important variables, make the results presented here highly tentative. In principle, and as further data become available it may be possible for researchers to assess the robustness of these results, and gain further insights on the forces behind the behavior of the peso/dollar rate in the post crisis period. A potential problem with this strategy, however, is that it is possible that in early 1998, and as a result of the appointment of anew governor, BOM has changed its monetary policy. ${ }^{50}$

\section{Concluding Remarks}

The Mexican peso crisis of December 1994 shocked politicians, analysts and pundits. Many asked how could a country wildly hailed as an example of economic strength collapse so rapidly. Shock was followed by panic, as domestic and international investors flew the country and tried to undo their positions. As 1995 unfolded it seemed increasingly clear that default on the rapidly maturing Tesobonos was more than a distant possibility. It took a massive bail out package put together by the IMF and the US Treasury to generate some tranquility in the markets in mid to late 1995.

From early on the Mexican authorities stated that stabilizing the value of the peso, within the context of a freely floating exchange rate regime, was one of their most important policy objectives. During most of 1995 this objective seemed to be highly elusive. Starting in 1996, however, the peso began to exhibit an impressive degree of stability. So much so that a number of analysts in the media and in academic and financial circles began to wonder whether this stability was consistent with a freely floating regime. Some even argued that it was "deja vu" all over again, and that the Bank of Mexico was manipulating monetary policy in order to maintain

\footnotetext{
${ }^{\text {so }}$ Naturally, once additional data are available it will be possible to test this hypothesis.
} 
artificially a strong peso. At the core of this concern was the notion that by following this policy BOM was setting the stage for another round of currency overvaluation that would end in a crash.

In this paper we have tried to explain the relative stability exhibited by the peso/dollar nominal exchange rate since late 1995 . Specifically, we approached this issue from two main angles: First, we asked whether the behavior of the peso/dollar rate since 1995 is broadly comparable or consistent with the behavior of a "typical" floating exchange rate. And our answer to this question was a qualified yes. Second, we explored whether during 1996-97 there was a relationship between the monetary policy followed by the BOM and the behavior of the peso/dollar rate. In particular, we asked whether the BOM followed some sort of feedback rule from the exchange rate to monetary policy. Our answer to this question was another qualified yes, but perhaps more strongly qualified than the first one.

We address the first question in Section III, where we used standard measures of exchange rate volatility (the mean absolute value of percentage changes and the standard deviation of percentage changes) to compare the behavior of the peso/dollar rate from 1991 to 1997 with that of seven other floating exchange rates--all of them from industrial countries. We conducted the comparison at daily, weekly and monthly frequencies for every year, and checked whether the "calendar year window" imposed arbitrary restrictions on the distribution of exchange rates that may prevent us from detecting important peculiarities in the behavior of the Mexican peso. The two most interesting findings that came out from this exercise were: first, that the degree of volatility of the Mexican peso in 1995 was an order of magnitude higher than that of the "typical" floating exchange rate; and second, that in 1996-97 the degree of volatility 
exhibited by the Mexican peso was broadly in line with that of the seven other currencies in the sample.

The first finding simply reflects that the financial mayhem that beset Mexico in 1995 turned the peso into a complete outlier in terms of volatility. This suggests to us that in periods where the fundamental issue is lack of confidence on the government's response to an external liquidity crisis--that is, in periods of widespread panic--there are simply no good yardsticks for assessing the behavior of floating exchange rates. The fundamental priority in those periods is to arrest the free-fall of the currency through a credible tightening of monetary policy. The second finding, on the other hand, suggests that the relative stability of the Mexican peso in 1996-97 was not "excessive" or grossly at odds with the behavior of other floating rates. True, the peso was less volatile than the currencies of the countries widely regarded as having the "cleanest" floats (the G-3 and the UK), but it was as or more volatile than other floating exchange rates.

In the second part of section III we applied the methodology developed by Flood and Rose (1995) to examine the relationship between nominal exchange rate volatility and macroeconomic volatility in several OECD countries to the case of Mexico. Our results suggest that, unlike the OECD experiences, the increase in volatility of the peso/dollar rate under the current float was accompanied by an increase in the volatility of some macroeconomic fundamentals. We took this as an indication that the evidence did not rule out the possibility that the determinants of nominal exchange rate volatility in Mexico between 1995 and 1997 were indeed of a macroeconomic nature. It also left open the possibility that the observed behavior of the peso/dollar rate was indeed related to the conduct of monetary policy.

We address the second question in section IV, where we look in greater detail at the relationship between exchange rate developments and monetary policy. More specifically, we 
analyzed whether (and to what extent) the BOM had used some type of feedback from the exchange rate to conduct its short-run monetary policy during 1996-97. There are three reasons why thought this question was particularly interesting: First, that the BOM has denied emphatically that it uses any type of feedback rule or mechanism from the exchange rate to monetary policy. Interestingly, it has done so in response to both criticisms and praises from outside observers about the alleged use of such a feedback since the adoption of the float. Second, many observers have been mystified by the BOM pronouncements regarding the way in which it conducts monetary policy. In particular, it is peculiar that the BOM (in its official and semi-official pronouncements) treats its day-to-day liquidity management operations as equivalent to its framework for monetary policy--rather than as an important but secondary part of it, as most central banks do. And third, and related to the other two, the BOM not only frames its discussion of monetary policy over extremely short horizons, but it allegedly relies on daily estimates of the demand for monetary base produced at the beginning of each year to guide its monetary policy. It is interesting to note that, as part of its efforts to increase the transparency of its actions, the BOM for the past two years has published these daily estimates of the demand for monetary base, presumably to make it easier for the public to understand and evaluate BOM's monetary policy and to serve as some sort of anchor for expectations.

In order to address the question of "What does BOM really do?", in section IV we reported results from four different, but related, types of analyses: First, we examined the basic time-series properties of a number of high-frequency monetary variables (the monetary base, interest rates, the exchange rate) and conducted simple Granger "causality-tests" for various pairs of these variables during 1996-97. Second, we looked at the behavior of these key variables in the period surrounding 30 large daily depreciations of the peso over the past 3 years (daily 
depreciations that range from 0.7 percent to 9 percent). Third, we estimated two trivariate VAR systems and calculated their impulse responses using weekly data from January 1996 to October 1997. And, finally, we estimated what we call--again with some hesitation--a monetary policy "reaction function" relating weekly changes in the monetary base to its targeted path and to a number of other variables, including the exchange rate. In our view, the results we obtained from all these analyses provide support to the conjecture that the BOM has systematically taken into account the behavior of the nominal exchange rate for conducting its short-run monetary policy during 1996-97. Specifically, we think that our results suggest quite strongly that during that period the BOM tightened monetary policy in response to large depreciations of the peso and, by doing so, contributed to dampen the short-run volatility of the nominal exchange rate.

Although it is too early for a final verdict, available evidence suggests that, in spite of some shortcomings, Mexico's monetary policy between 1995 and 1997 contributed to the achievement of two policy objectives: it helped arrest the free fall in the value of the peso, and it helped reduce inflation at a pace that very few observers deemed achievable in early 1995 . Our analysis, however, has not touched on whether, as some influential observers have argued, by pursuing this policy Mexico came dangerously close to, once again, overvaluing its real exchange rate. A detailed analysis of the Mexican post 1994 experience would prove useful to East Asian policy makers that, in early 1997 , are desperately seeking to stabilize the value of their currencies. 


\section{REFERENCES}

Aguilar, A. and V.H. Juan-Ramón (1997), "Determinantes de la tasa de interés de corto plazo en México: efecto de las señales del banco central," Gaceta de Economia, ITAM, 3, 5 (Fall)

Andrews, D. and S. Ishii (1995), "The Mexican Financial Crisis: A Test of the Resilience of the Markets for Developing Country Securities," IMF Working Paper WP/95/132, Washington, D.C., November

Aspe, P. (1993), Economic Transformation the Mexican Way, Cambridge, Mass: MIT Press

Baillie, R. and P. McMahon (1989), The Foreign Exchange Market: Theory and Econometric Evidence, Cambridge, U.K.: Cambridge University Press.

Banco de Mexico, The Mexican Economy,(several issues), Mexico D.F.: Banco de Mexico

Bernanke, B. and I. Mihov (1997), "What does the Bundesbank Target?" European Economic Review, Vol 41: 1025-1053

Calvo, G. (1994), "Comments and Discussion," (comments on Dornbusch and Werner) Brookings Papers on Economic Activity 1: 1994

Calvo, G. (1995), "Varieties of Capital Market Crises," Working Paper No.15, Center for International Economics, University of Maryland, College Park, November

Calvo, G. and E. Mendoza (1996), "Mexico's balance-of-payments crisis: A chronicle of a death foretold," Journal of International Economics, (special issue), Vol 41, Nos. 3/4, November

Clarida, R. and M. Gertler (1997), "How the Bundesbank Conducts Monetary Policy," in C.Romer and D.Romer (eds) Reducing Inflation, Chicago: The University of Chicago Press

Copelman, M. and A. Werner (1997), "El Mecanismo de la Trasmisión Monetaria en México," El Trimestre Económico, Vol 64: 75-104

D'Amato, A. (1995), Report on the Mexican Economic Crisis, United States Senate, June 29, 1995

De Long, B., C. De Long and S. Robinson (1996), "In defense of Mexico's rescue," Foreign Affairs, Vol. 75, May/June

de Vries, C. (1994), "Stylized Facts of Nominal Exchange Rate Returns," in F.van der Ploeg (ed.) The Handbook of International Macroeconomics, Cambridge, Mass: Basil Blackwell 
Dornbusch, R. (1993), "Mexico: How to Recover Stability and Growth," chapter 17 in his Stabilization, Debt, and Reform, New Jersey: Prentice Hall

Dornbusch, R. and A. Werner (1994), "Mexico: Stabilization, Reform, and No Growth," Brookings Papers on Economic Activity 1: 1994, pp 253-297

Dornbusch, R., I. Goldfajn and R. Valdés (1995), "Currency Crises and Collapses" Brookings Papers on Economic Activity 2: 1995, pp 219-293

Dornbusch, R. (1997), Business Week Column (several issues)

Edwards, S. (1996), "Exchange Rate Anchors, Credibility and Inertia: A Tale of Two Crises, Chile and Mexico," American Economic Review Papers and Proceedings, May

Edwards, S. (1997), "The Mexican Peso Crisis: Bad Luck or Bad Policies?" mimeo, University of California, Los Angeles

Edwards, S. (1998a), "Two Crises: Inertia, Exchange Rates and Inflation" The Economic Journal, (forthcoming)

Edwards, S. (1998b), "The Mexican Peso Crisis: How Much did we Know? When did We Know it?" The World Economy, (forthcoming)

Edwards, S., R. Steiner and F. Losada (1996), "Capital Flows, the Real Exchange Rate and the Mexican Crisis," mimeo, World Bank

Federal Reserve Bank of Kansas City (1996), Achieving Price Stability, proceedings from the August 1996 symposium held at Jackson Hole, Wyoming

Fischer, S. (1994),"Comments and Discussion," (comments on Dornbusch and Werner) Brookings Papers on Economic Activity 1: 1994

Flood, R. and A. Rose (1995), "Fixing exchange rates: A virtual quest for fundamentals," Journal of Monetary Economics, Vol 36: 3-37

Frankel, J. (1979), "On the Mark: a Theory of Floating Exchange Rates Based on Real Interest Rates Differentials," American Economic Review, Vol.69:610-22

Frankel, J. and A. Rose (1995), "A Survey of Empirical Research on Nominal Exchange Rates," in G.Grossman and K. Rogoff (eds) Handbook of International Economics, Vol 3, Amsterdam: North Holland

Froot, K. and K. Rogoff (1995), "Perspectives on PPP and Long-Run Real Exchange Rates," in G.Grossman and K. Rogoff (eds) Handbook of International Economics, Vol 3, Amsterdam: North Holland 
Galindo, L. (1997), "El modelo $\mathrm{P}^{*}$ como indicador de la política monetaria en una economía con alta inflación," El Trimestre Económico, Vol 64: 221-239

Gil-Díaz, F. and A. Carstens (1996), "One Year of Solitude: Some Pilgrim Tales About Mexico's 1994-95 Crisis," American Economic Review Papers and Proceedings, May

Gil-Díaz, F. (1997), "La Política Monetaria y sus Canales de Transmision en México", Gaceta de Economia, ITAM, 3, 5 (Fall)

International Monetary Fund (1995a), "Factors Behind the Financial Crisis in Mexico," Annex I of World Economic Outlook, Washington, D.C.: IMF, May

International Monetary Fund (1995b, 1996), International Capital Markets: Developments, Prospects and Policy Issues, Washington, D.C.: IMF, August (1995), September (1996)

Isard, P. (1995), Exchange Rate Economics, Cambridge, U.K.: Cambridge University Press.

Issing, O. (1997), "Monetary Targeting in Germany: The stability of monetary policy and of the monetary system," Journal of Monetary Economics, Vol 39:67-74

Kamin, S. and J. Rogers, "Output and the real exchange rate in developing countries: An application to Mexico," International Finance Discussion Papers No. 580, Washington, D.C.: Board of Governors of the Federal Reserve System

Krugman, P. (1995), "Dutch Tulips and Emerging Markets," Foreign Affairs, Vol.74, No.4 July/August

Leiderman, L. and A. Thorne (1995), "Mexico's 1994 Crisis and its Aftermath: Is the Worst Over?," mimeo, Tel-Aviv University, August

Loser, C. and E. Kalter (eds) (1992), Mexico: The Strategy to Achieve Sustained Economic Growth, IMF Occasional Paper 99, Washington, D.C.: IMF, September

Lustig, N. (1992), Mexico: The Remaking of an Economy, Washington, D.C.: The Brookings Institution

Lustig, N. (1995), "The Mexican Peso Crisis: The Foreseeable and the Surprise," Brookings Discussion Papers in International Economics No. 114, Washington, D.C., June

Malpass, D. (1997) "Free Float to Disaster", The Wall Street Journal, October 20, 1997.

Masson, P. and P.R. Agenor (1996), "The Mexican Peso Crisis: Overview and Analysis of Credibility Factors," IMF Working Paper WP/96/6, Washington, D.C., January

Milesi-Ferretti, G.M. and A. Razin (1996), "Current-Account Sustainability," Princeton Studies 
in International Finance No. 81, New Jersey: Princeton University, October

Obstfeld, M. and K. Rogoff (1995), "The Mirage of Fixed Exchange Rates," The Journal of Economic Perspectives, Vol 9, No. 4, Fall 1995

O’Dogherty, P. (1997), "La instrumentación de la política monetaria en México,"Gaceta de Economia, ITAM, 3, 5 (Fall)

OECD (1996), OECD Economic Surveys 1996-1997: Mexico, Paris: OECD, December

Ortiz, G. (1994), "Comment on R. Dornbusch:'Stabilization and Reform in Latin America'," in J.O. de Beaufort Wijnholds et al. (eds) A Framework for Monetary Stability, Boston: Kluwer Academic Publishers

Reisen, H. (1995), "Managing Temporary Capital Inflows: Lessons from Asia and Latin America," mimeo, Paris: OECD Development Centre

Reynoso, A. (1995), "Sostenibilidad de la Política Cambiaria en Economías Pequeñas," Documento de Investigación No.68, Banco de México, July

Romer, C. and D. Romer (eds) (1997), Reducing Inflation, Chicago: The University of Chicago Press

Rose, A. (1994), “Are Exchange Rates Macroeconomic Phenomena?” Federal Reserve Bank of San Francisco Economic Review No.1

Sachs, J., A. Tornell and A. Velasco (1996), "The Collapse of the Mexican Peso: What Have We Learned?" Economic Policy: A European Forum, No. 22, April

Santaella, J. and A. Vela (1996), "The 1987 Mexican Disinflation Program: An Exchange RateBased Stabilization?" IMF Working Paper WP/96/24, Washington, D.C., March

Taylor, J. (1993), "Discretion versus policy rules in practice," Carnegie-Rochester Conference Series on Public Policy, Vol 39: 195-214

The Economist (1998), “The Lingering Tequila Effect", March 14-28

Vela, A. (1993), "Three Essays on Inflation and Stabilization: Lessons from the Mexican Solidarity Pact," unpublished Ph.D. Dissertation, University of California, Los Angeles

Warner, A. (1997), "Mexico's 1994 exchange rate crisis interpreted in light of the non-traded model," NBER Working Paper 6165, Cambridge, Mass.

Werner, A. (1996), "Mexico's Currency Risk Premia in 1992-94: A Closer Look at the Interest Rate Differentials," IMF Working Paper WP/96/41, Washington, D.C., April 
Werner, A. (1997), "Un estudio estadístico sobre el comportamiento de la cotización del peso mexicano frente al dólar y de su volatilidad,"Gaceta de Economia, ITAM, 3, 5 (Fall)

Williamson, J. (ed) (1995), Estimating Equilibrium Exchange Rates, Washington, D.C.: Institute for International Economics 
FIGURE 1. MEXICO: Capital fiows and Real Exchange Rate (1980-94)

K. Acc.

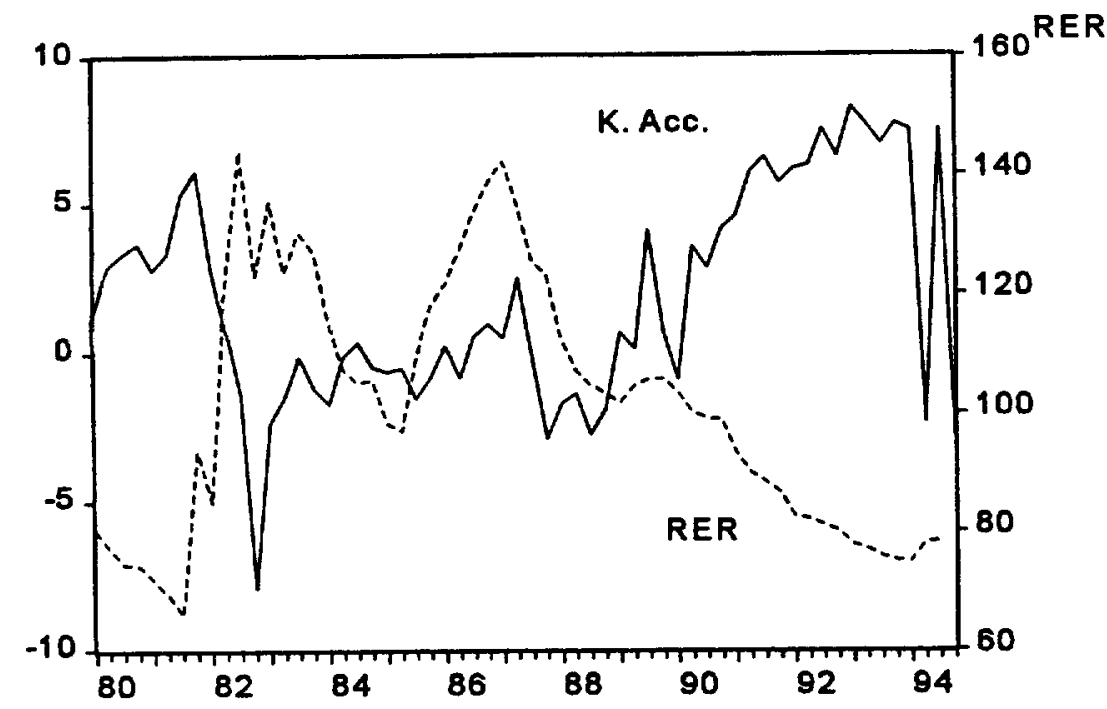

Capital flows in US $\$$ billion (left scale) RER index $1990=100$ (right scale) Source: Banco de Mexico and IMF 
Figure 2. Mexico: Nominal and Real Exchange Rate

(Jan 1991- Nov 1997)

\section{A. Mexican pesos per U.S. dollar}

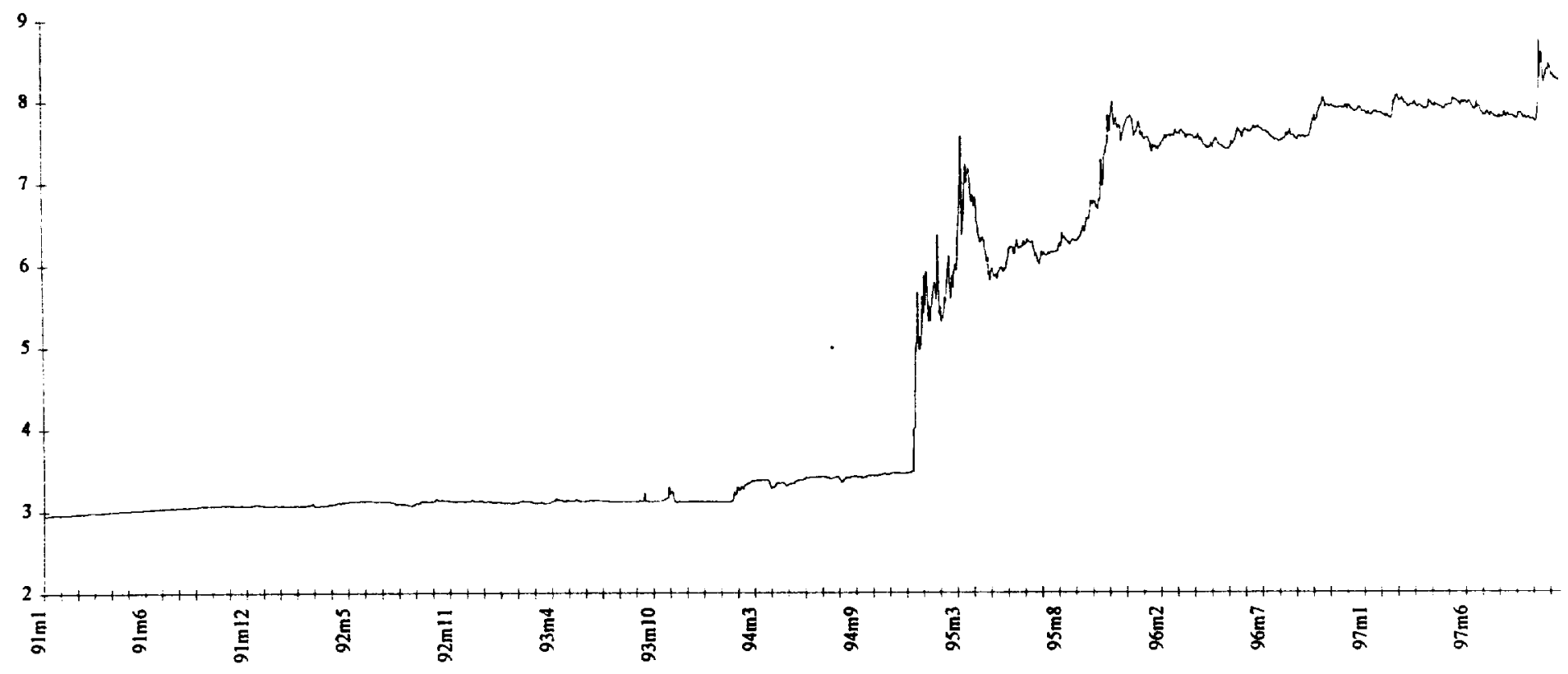

B. Real Exchange Rate vis-a-vis US dollar *

CPI based, $(1990=100)$

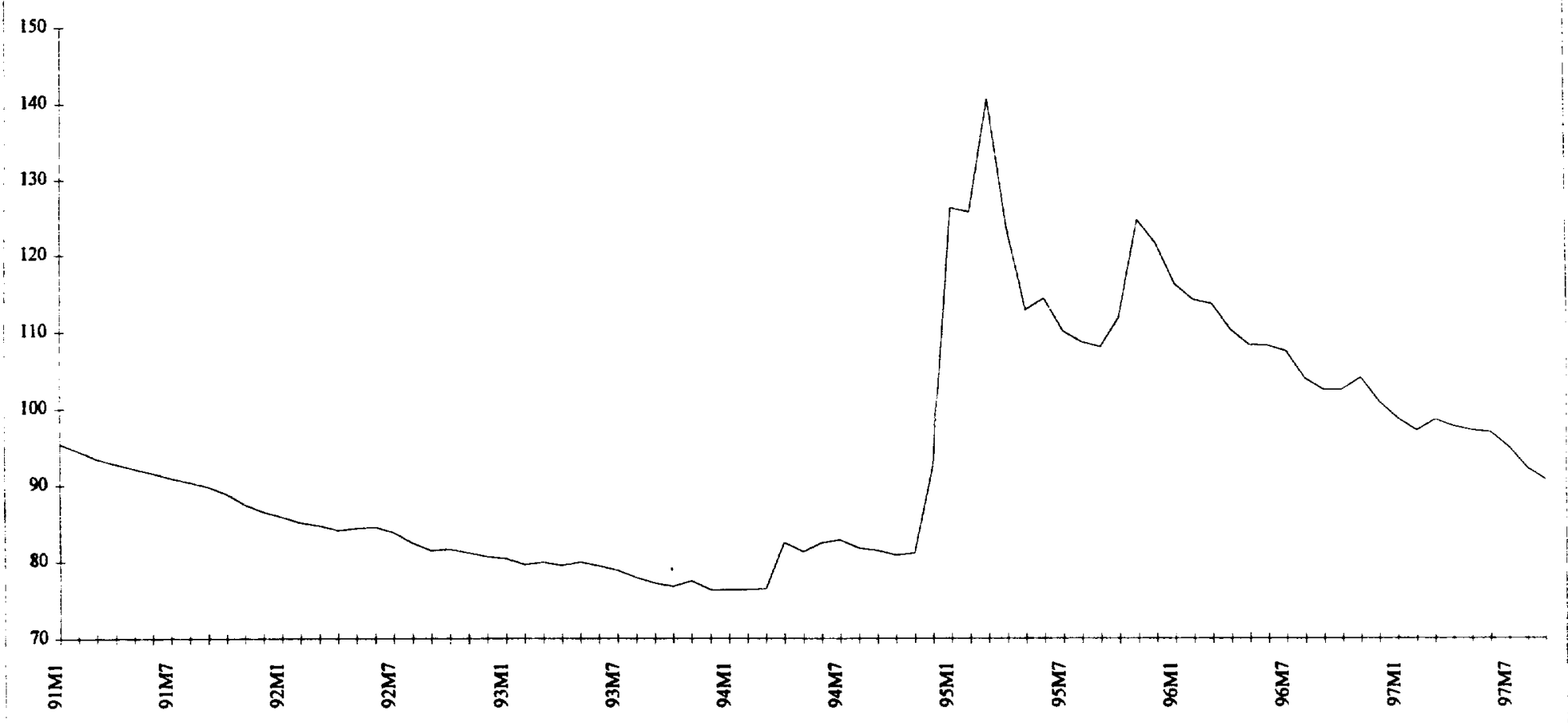



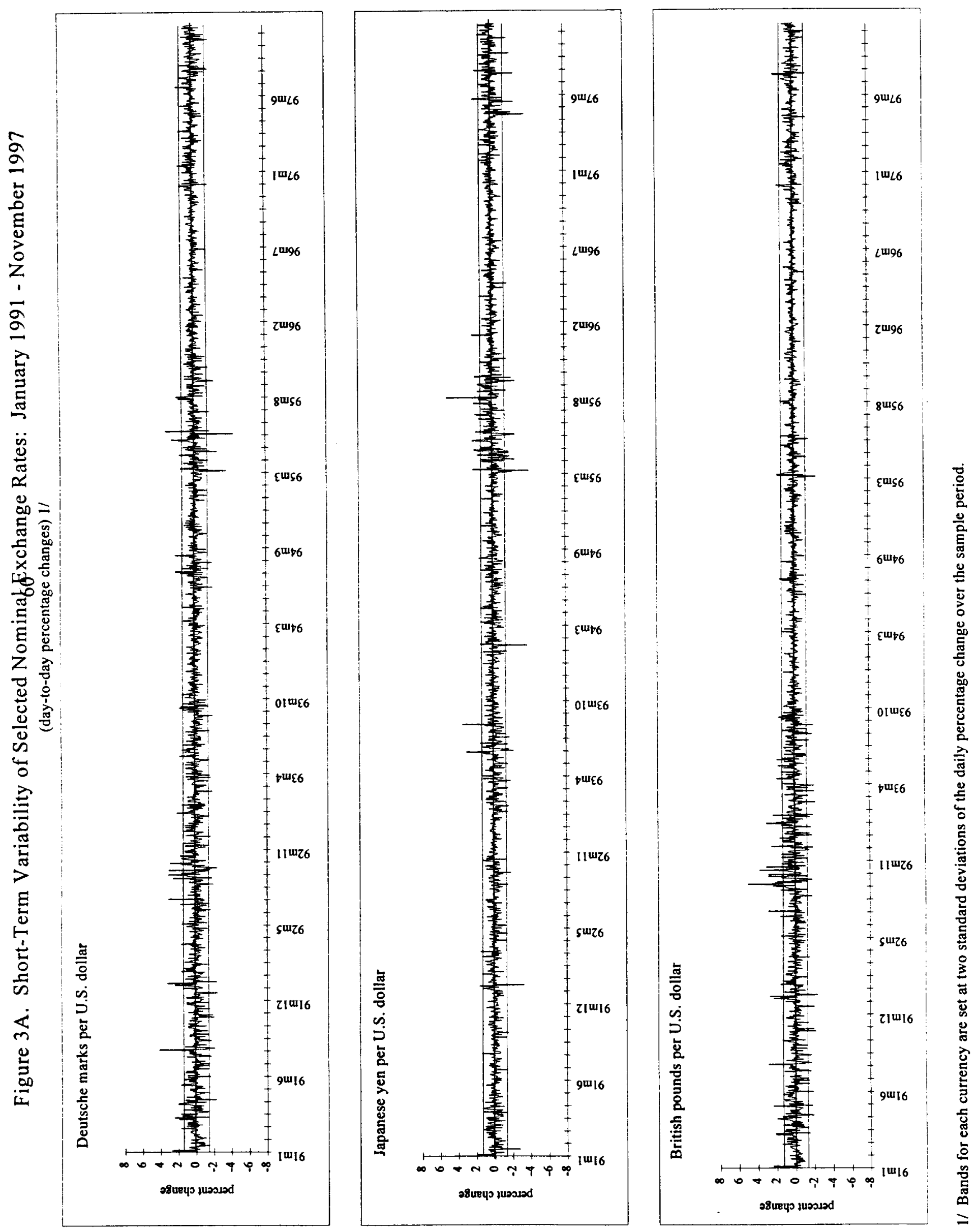

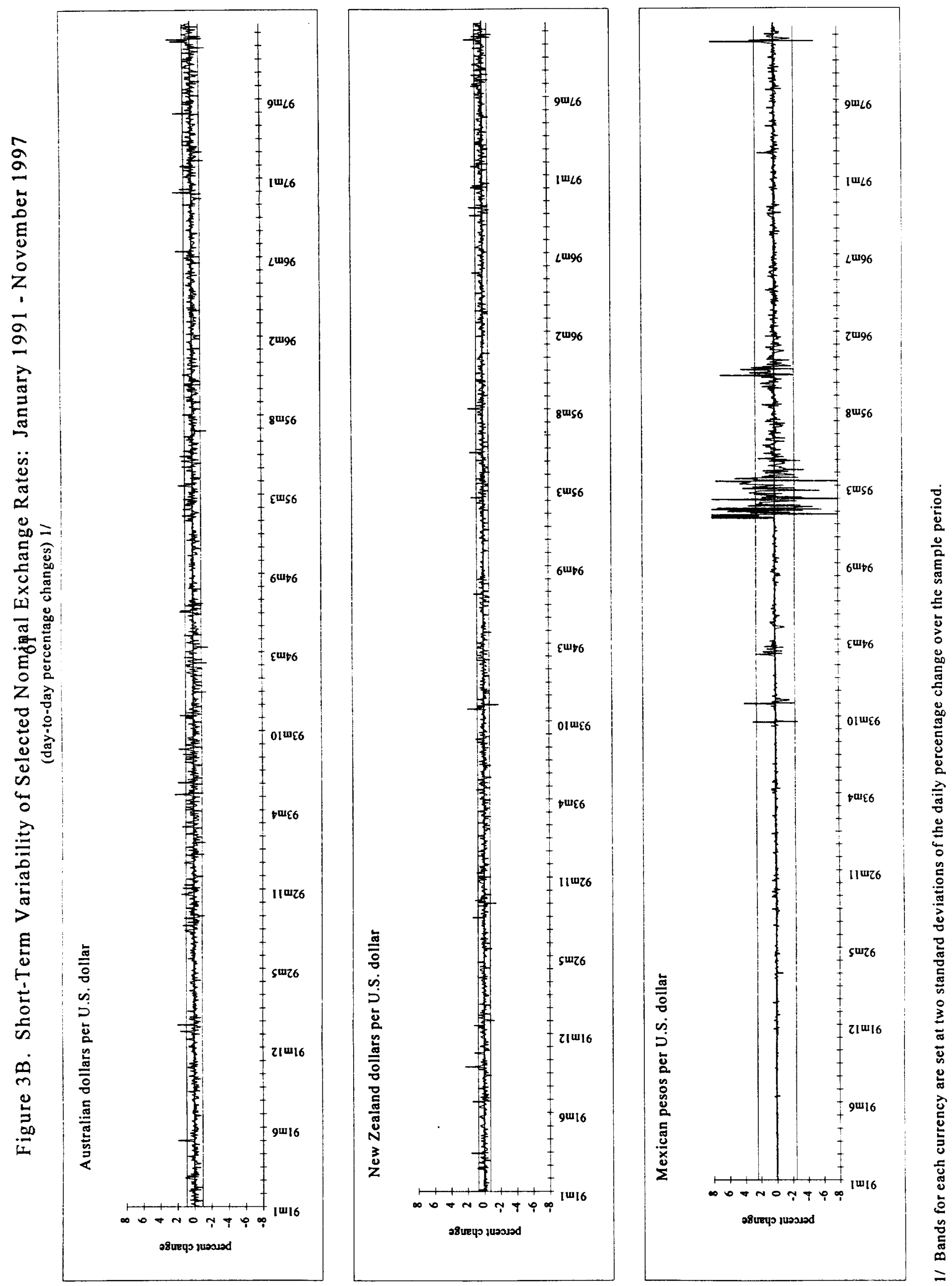

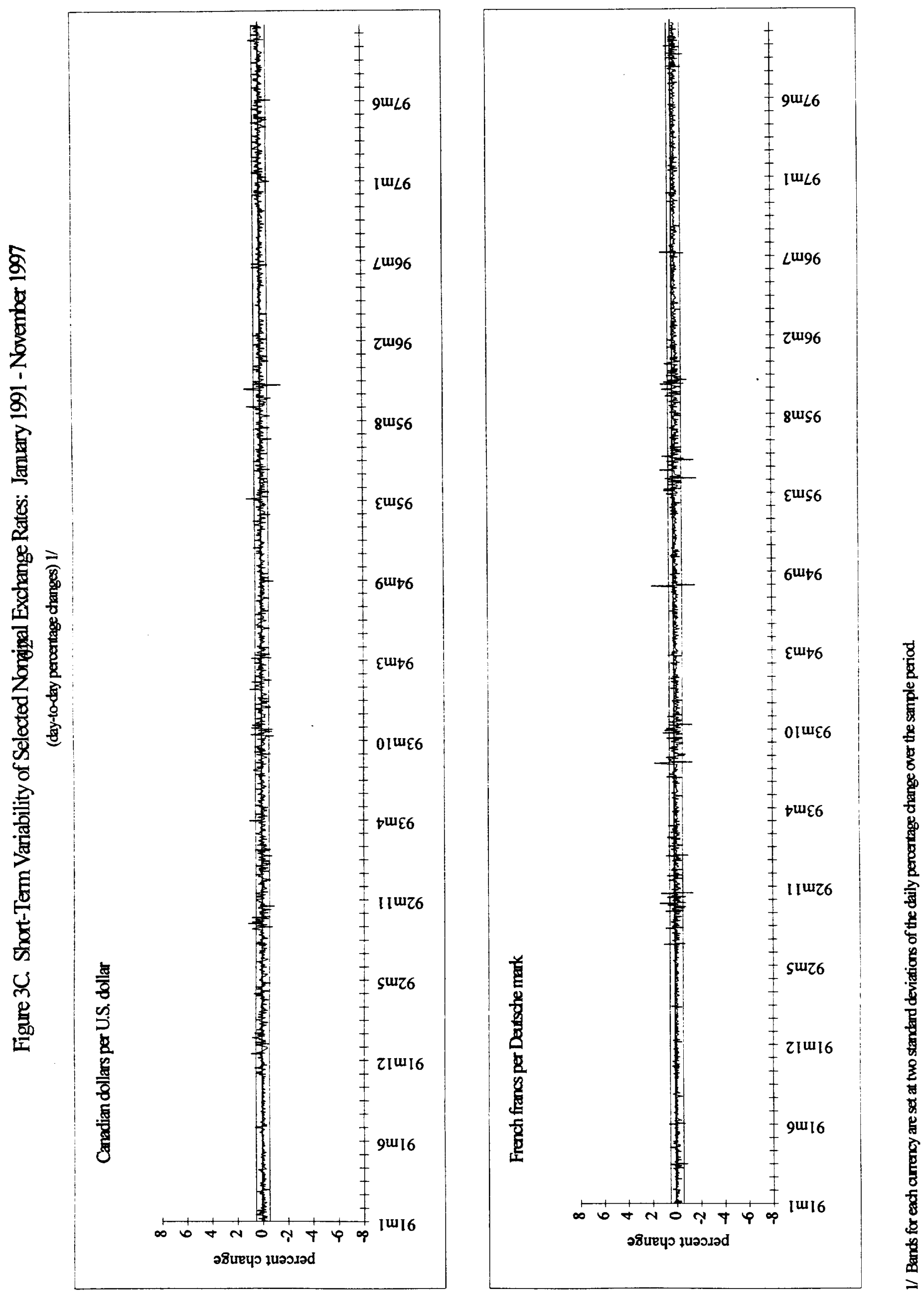
Figure 3D. Short-Term Variability of Nominal Exchange Rates, Jan. 96 - Nov. 97

(day to day percentage changes)

Australian dollars per U.S. dollar

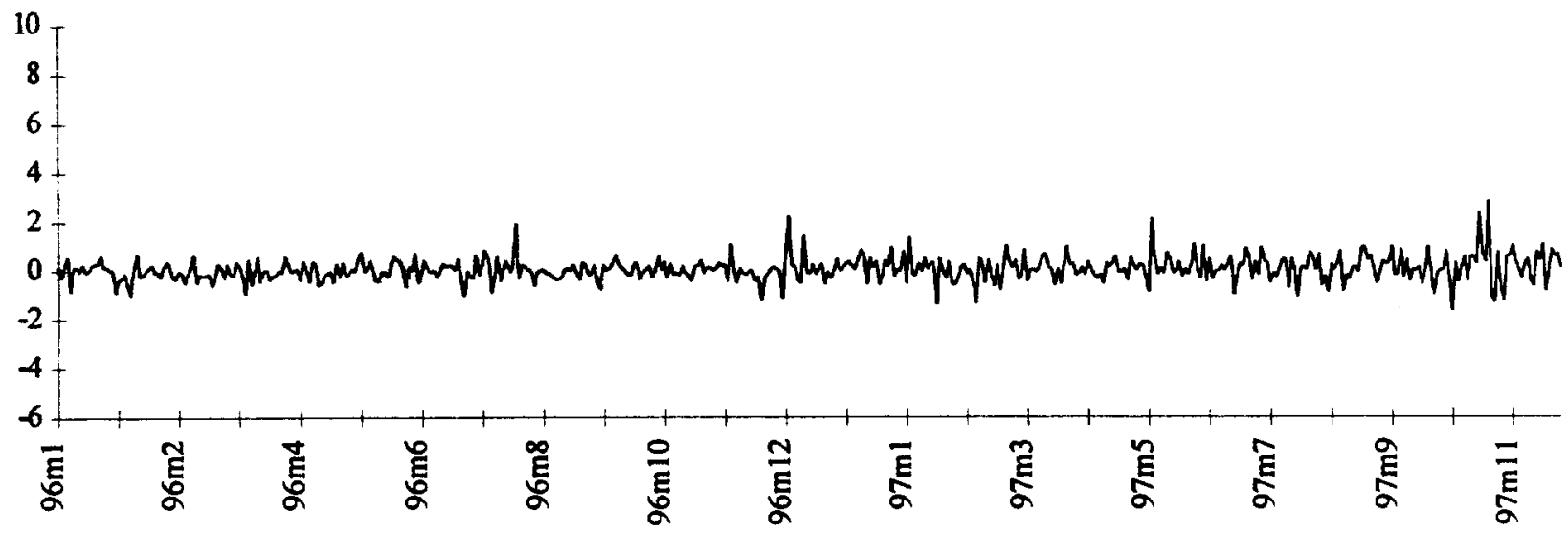

New Zealand dollars per U.S. dollar
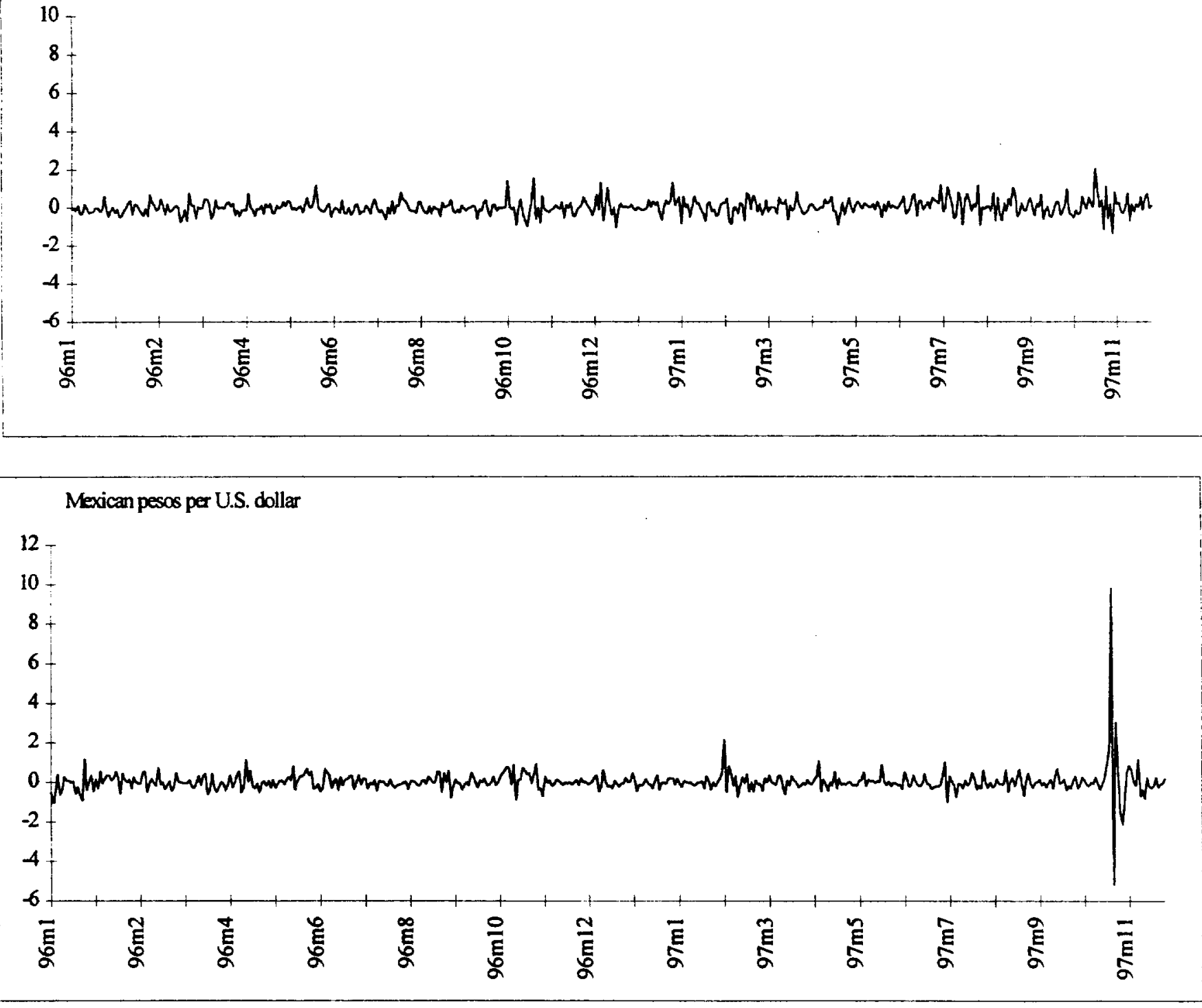
Figure 4. Mexican Peso: "Virtu64" and "Traditional" Fundamentals

(January 1991 - October 1997)
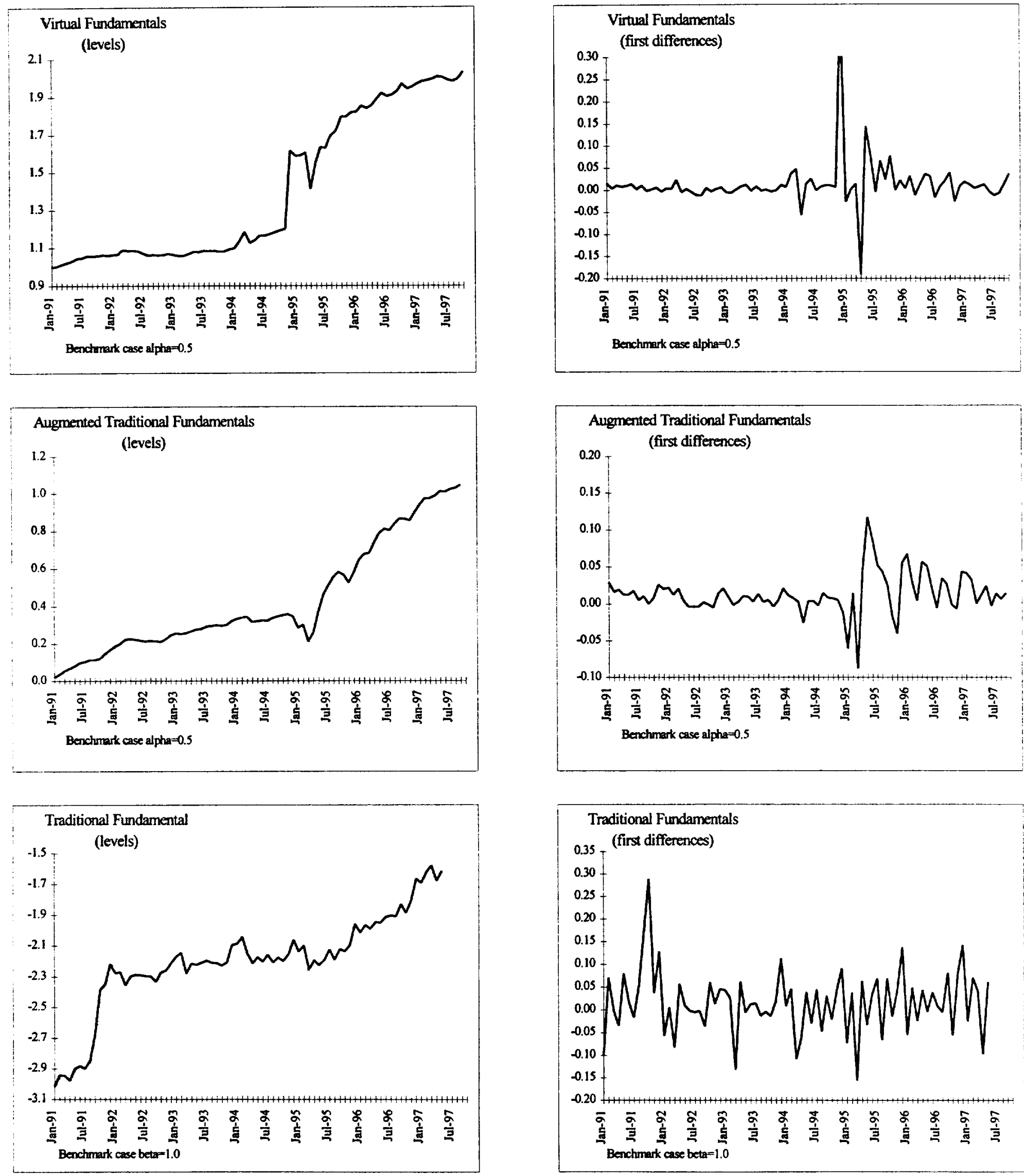
Eigure 5:

Mexico: Daily peso/dollar rate and daily Cates rate (secondary market)

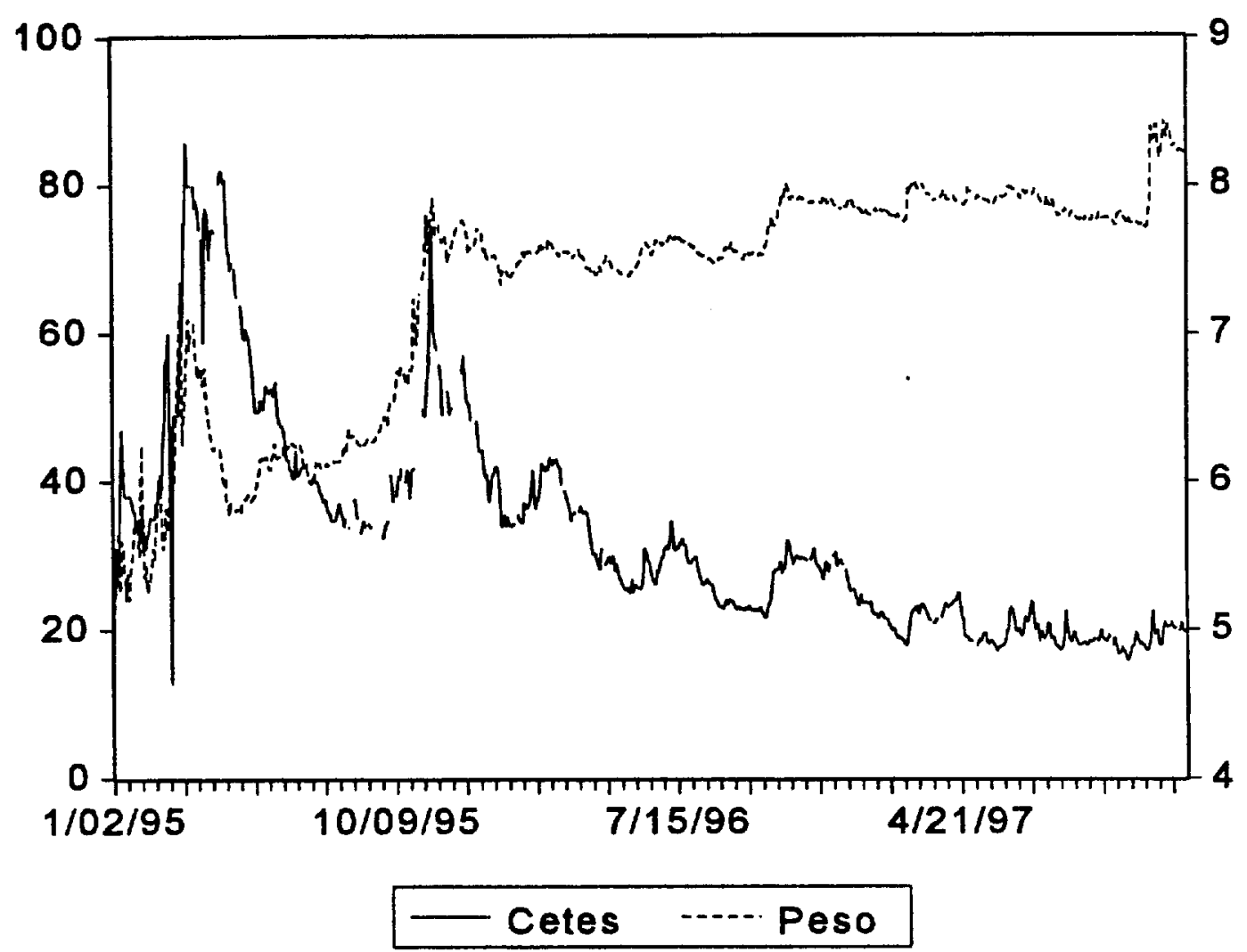


Figure 6: Actual and Target Monetary Base: Daily Data, 1996-97

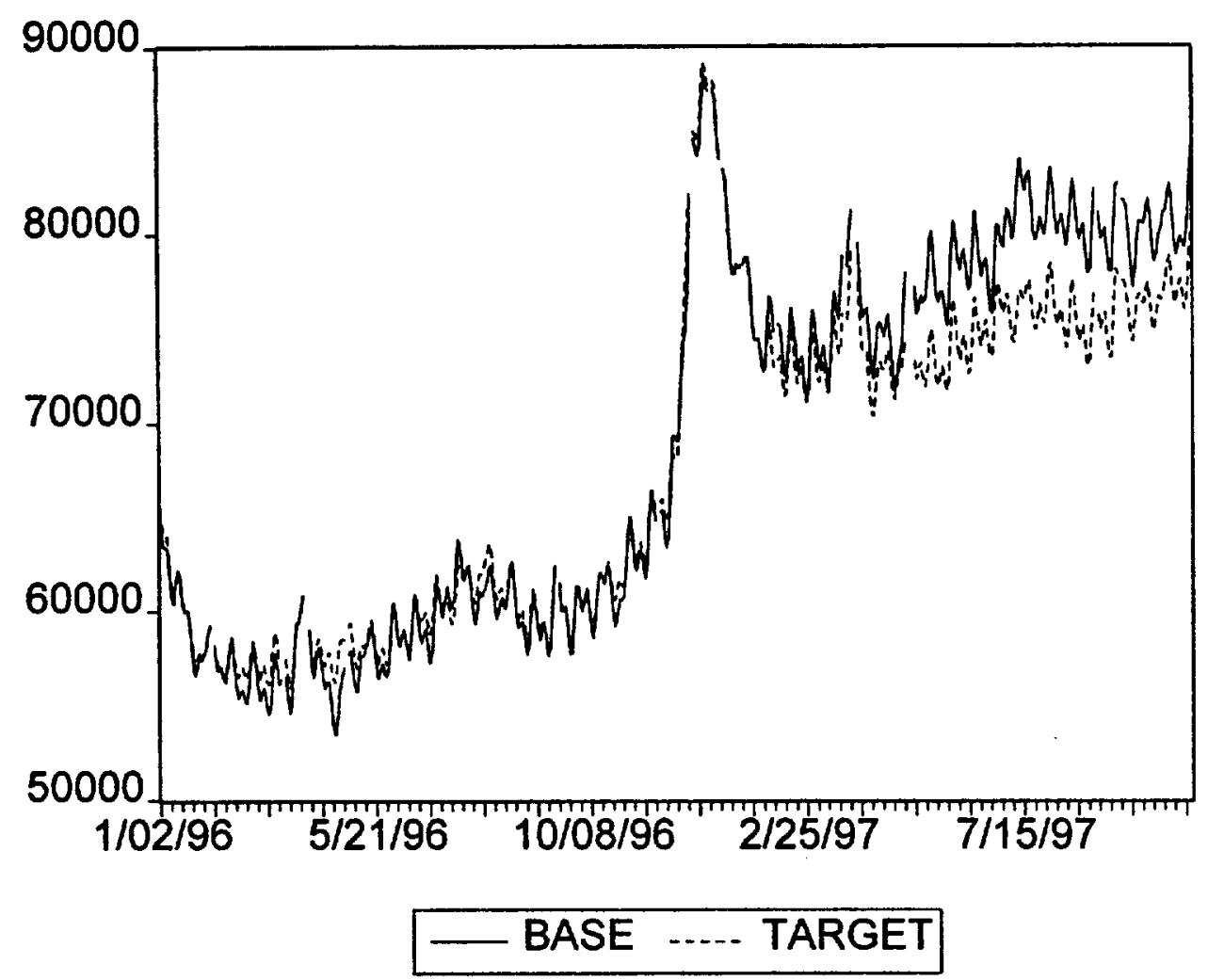


Figure 7A: Excess Liquidity Index:

Daily Data, 1996-1997

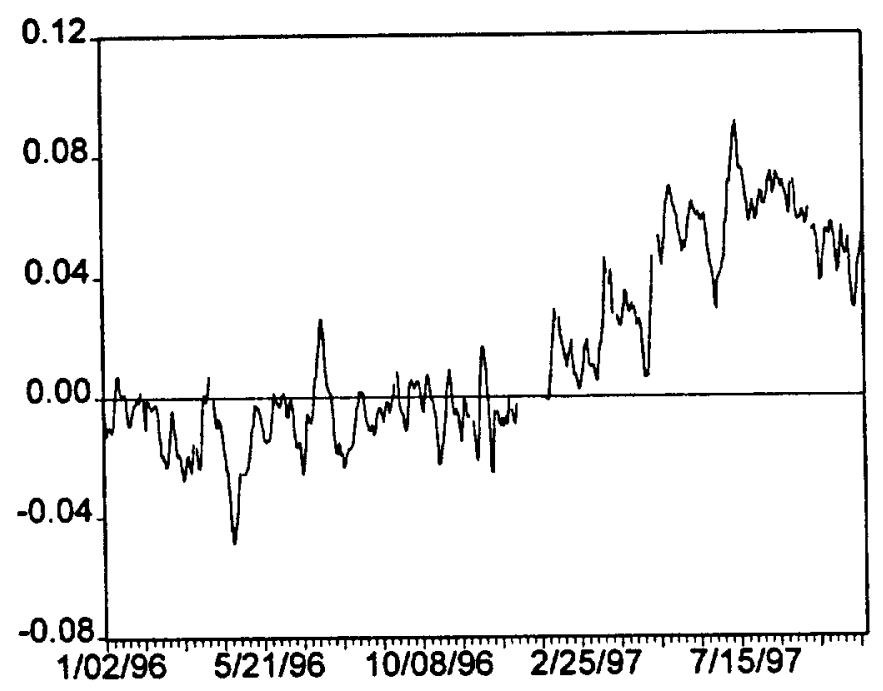

Figure 7B: Excess Liquidity Index: Detrended, Daily Data 1996-97

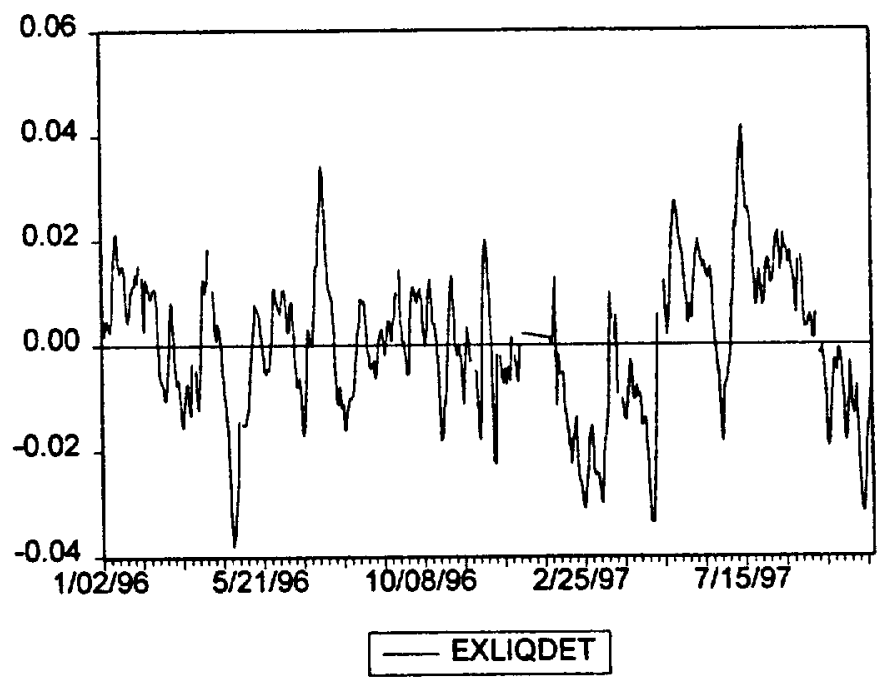


Figure 8A: Impulse Response Functions: VARI Model, Woekly Data

Response of (LBASE-LPROG) to One S.D. Innovations

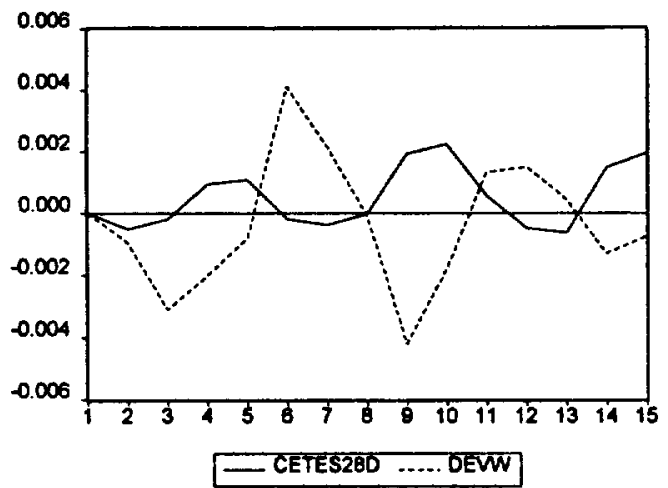

Response of CETES28D to One S.D. Innovations

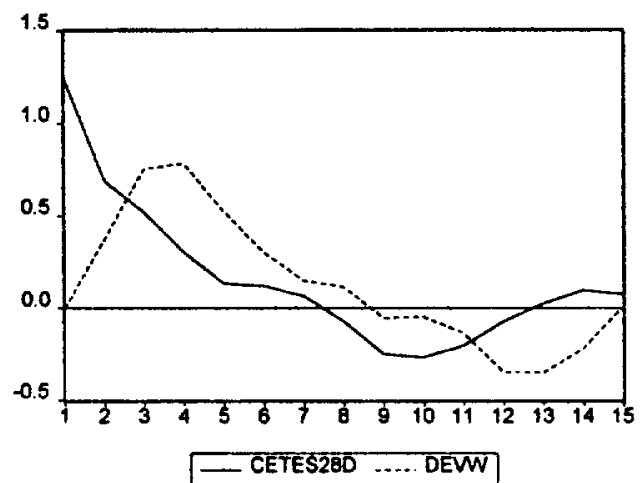

Response of DEWW to One S.D. Innovations

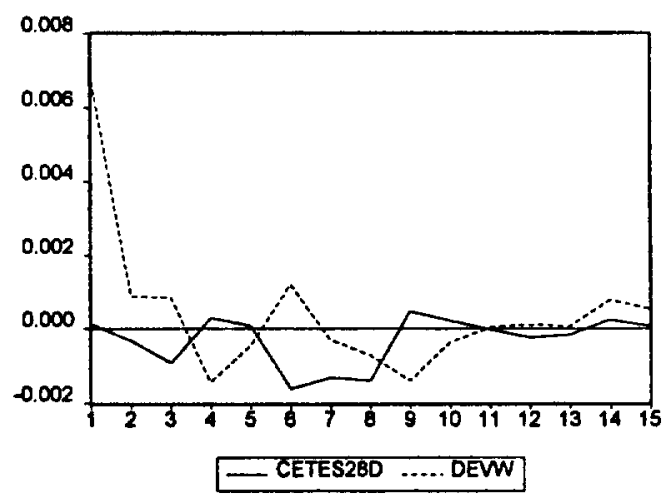


Figure 8B: Impulse response Functions. VAR2 Model. Weekly Data

Response of DLBASE to One S.D. Innovations

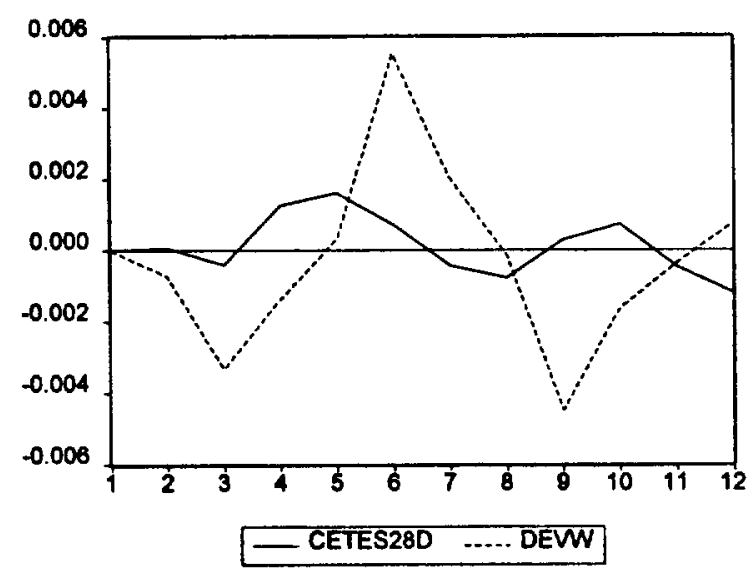

Response of CETES28D to One S.D. Innovations
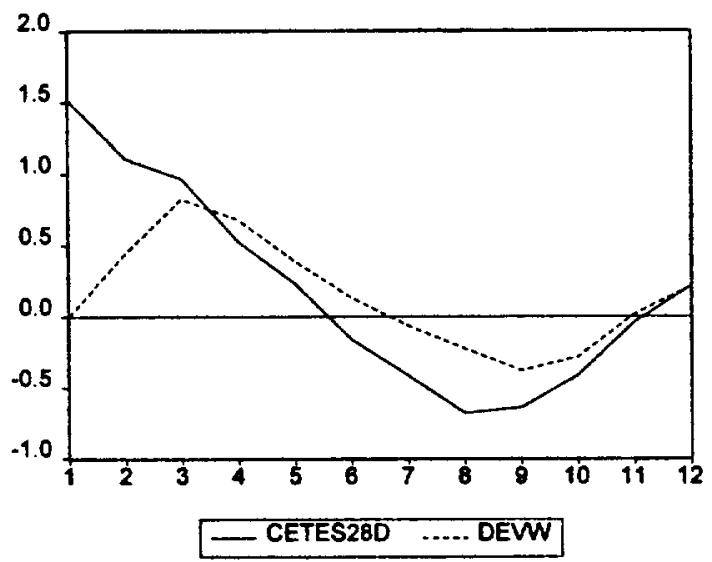

Response of DEWW to One S.D. Innovations

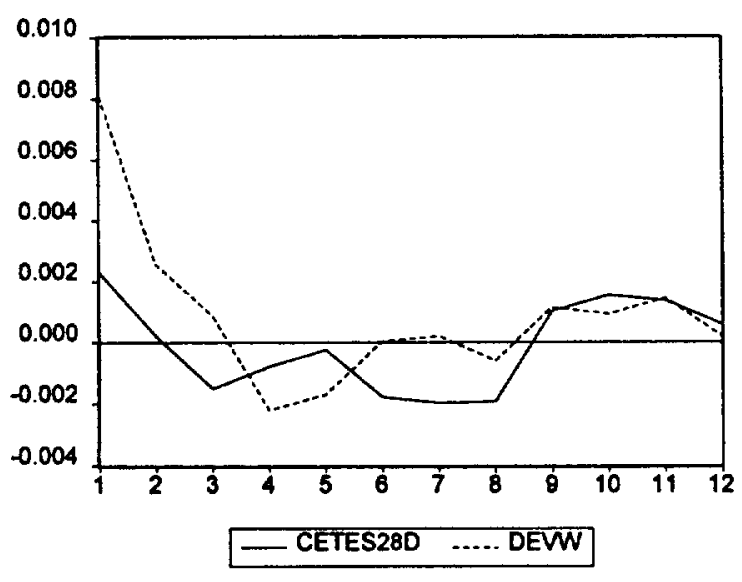


Table 1. Volatility of Daily Exchange Rates

1991

Number of obs.

Mean absolute percentage change

Stundard deviation of pct. chge

Meximum absolute pet. chge

Number of obs. with zero change 1 /

1992

Number of obs.

Mean absolute percentage change

Standard deviation of pet. chge

Maximum absolute pet. chge

Number of obs. with zero change $1 /$

1993

Number of obs.

Mean absolute percentage change

Standard deviation of pet chge

Maximum absolute pet. chge

Number of abs. with zero change 1/

1994

Number of obs.

Mean absolute percentage change excluding Dec 20-Dec 31 Standard deviation of pet. chge excluding Dec 20-Dec31

Maximum absolute pct. chge

Number of obs. with zero change I/ 1995

Number of obs.

Mean absolute percentage change

Standard deviation of pct chge

Maximum absolute pct. chge

Number of obs. with zero change $/ /$

1996

Number of obs.

Mean absolute percentage change

Standard deviation of pet. chge

Maximum absolute pet. chge

Number of obs. with zero change if 1997 (Jan-Nov)

Number of obs.

Mean absolute percentage change

Standard deviation of pet. chge

Maximum absolute pct. chge

Number of obs. with zero change $1 /$

1991-1997 2f

Number of obs.

Mean absolute percentage change

Standard deviation of pct. chge

Maximum absolute pet. chge

Number of obs. with zero change I/

Number of obs. with zero change I/ $\quad 69$

2/ Up to end-November 1997

\begin{tabular}{|c|c|c|c|c|c|c|c|}
\hline $\begin{array}{l}\text { Germany } \\
\text { DM / US dollar }\end{array}$ & $\begin{array}{c}\text { Japan } \\
\text { yea/ USdoller }\end{array}$ & $\begin{array}{c}\text { UK } \\
\text { pound/USdollar }\end{array}$ & $\begin{array}{c}\text { Canada } \\
\text { Cans/US dollar }\end{array}$ & $\begin{array}{c}\text { Australia } \\
\text { ASJUS dollar }\end{array}$ & $\begin{array}{l}\text { New Zealand } \\
\text { NZS/US dollar }\end{array}$ & $\begin{array}{l}\text { France } \\
\text { FFr/DM }\end{array}$ & $\begin{array}{c}\text { Mexico } \\
\text { peso/US dollar }\end{array}$ \\
\hline
\end{tabular}

258

0.6066

0.8533

4.1440

12

260

0.6505

0.8922

3.1903

9

260

0.5340

0.6935

2.1211

9

260

0.4501

0.6006

2.1824

10

259

0.5474

0.8032

4.4128

9

260

0.3202

0.4290

1.7236

12

237

0.4739

0.6086

1.8414

8

1794

0.5122

0.7142

4.4128

69

14

257

257

$\begin{array}{ll}257 & 0.2658\end{array}$

0.1802

0.9158

15

2.8290
9

24

0.4069

0.5611

3.2460

20

0.6701

0.9520

5.0254

9

0.4818

0.6734

3.4568

24

\subsection{2}

0.7839

3.0316

9

0.4567

0.3071

0.6179

0.4194

3.7665

20

1.5282

9

0.6307

0.9214

5.0721

14

0.3435

0.4874

2.4375

10

0.3435

0.4557

2.2562

22

0.3556

1.6238

8

0.5167

0.7174

3.6526

21

0.4045

0.5352

2.0122

5

0.2226

0.2969

1.1503

9

$\begin{array}{ll}0.2658 & 0.2510\end{array}$

0.3639

1.9577

1.957
12

0.3704

2.3219

23

0.1206

0.1765

0.8803

13

0.0495

0.0821

0.4904

18

.1025

0.1635

$0.4188 \quad 0.2505$

$2.0030 \quad 1.5042$

33

0.2867

1.4214

0.8406

12

0.2346

0.3076

1.0413

0.4106

0.5479

2.2455

13

0.2634

0.3756

1.9604

0.2257

0.3423

1.8054

13

0.4423

4.0609

9

0.1946

0.3059

0.2193

0.1434

0.4379

0.2630

0.4533

0.3011

0.2364

0.1813

1.9721

0.2913

0.9530

1.7561

1.1191

1.9889

15

30

0.2311

0.3281

1.6231

0.3569

0.4818

1.7140

0.2660

0.3653

1.7509

0.2553

0.3707

17

1.3144

2.3005

15.8940

0.1396

0.1922

0.6616

0.2838

0.4042

2.1690

15

0.3504

1.5314

16

0.1285

0.1866

1.1580

13

0.2592

0.3461

1.1565

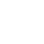

0.1981

0.2585

0.9679

0.4209

0.5726

2.7822

9

0.3356

0.4471

2.0083

0.1459

0.2039

0.8352

12

8

19

0.3329

0.4677

0.2610

0.3686

0.1717

0.2676

1.9889

92

167

115

82

59

ren

( 
Table 2. Volatility of Weekly Exchange Rates (end-of-week exchange rate)

\begin{tabular}{|c|c|c|c|c|c|c|c|}
\hline $\begin{array}{c}\text { Germany } \\
\text { DM NS dollar }\end{array}$ & $\begin{array}{c}\text { Jepan } \\
\text { yen/USdollar }\end{array}$ & $\begin{array}{c}\text { UK } \\
\text { pound/USdollar }\end{array}$ & $\begin{array}{c}\text { Caneda } \\
\text { Cans/US dollar }\end{array}$ & $\begin{array}{c}\text { Australia } \\
\text { ASIUS dollar }\end{array}$ & $\begin{array}{l}\text { New Zealand } \\
\text { NZSJUS dollar }\end{array}$ & $\begin{array}{l}\text { France } \\
\text { FFr/DM }\end{array}$ & $\begin{array}{c}\text { Mexico } \\
\text { peso/US dollar }\end{array}$ \\
\hline
\end{tabular}

1991

Number of obs.

Mean absolute pereentage change Standard deviation of pet. chge Maximum absolute pet. chge Number of weeks with zero change 1992

Number of obs.

Mean absolute percentuge change Sundard deviation of pet. chge Maximum absolute pet. chge Number of weeks with zero change 1993

Number of obs.

Mean absolute percentuge change Standard deviation of pet. chge

Maximum absolute pet. chge

Number of weeks with zero change 1994

Number of obs.

Mean absolute percentage change excluding last two weeks of Dec Standard deviation of pct. chge

excluding tast two weeks of Dec Maximum absolute pet. chge

Number of weeks with zero change 1995

Number of obs.

Mean absolute percentage chenge

Standard deviation of pet. chge

Maximum absolute pat. chge

Number of weeks with zero change 1996

Number of obs.

Mean absolute percentage change

Standard deviation of pct. chge

Maximum absolute pet. chge

Number of weeks with zero change 1997 (Jan -Nov)

Number of obs.

Mean absolute percentage change

Standard deviation of pct. chge

Maximum absolute pct. chge

Number of weeks with zero change

1991-1997 1/

Number of obs.

Mean absolute percentage change

Standard deviation of pct. chge

Maximum absolute pet. chge

Number of weeks with zero change

51

1.5918

1.9114

4.4849

0

$\begin{array}{ll}0.8843 & 1.4403 \\ 1.1877 & 1.7526\end{array}$

1.1877

2

53

1.4656

1.8843

4.6834

0

0.9306

1.1691

3.0313

$\$ 2$

1.1605

1.4529

4.0163

0

1.2546

3.5285

52

0.9526

0.8317

0.7019

$\begin{array}{ll}1.2035 & 1.1292\end{array}$

1.5399
2.2629
11.3738

3.4196

2.5835

1

2

52

1.1319

1.6206

5.3676

0

1.4128

1.8974

5.3162

0

52

0.6358

0.8435

2.1930

0

0.8034

0.9448

2.1091

0

48

1.0502

1.2782

3.2729

1.1412

1.5171

5.2760

0

360

1.1867

1.5453

5.3676

0.9956

1.3090

5.3162

$\begin{array}{r}5 \\ \hline\end{array}$
3.5161
0

0.9341

0

1.2965

1.6097

3.9243

0

2.4401

0

0.6646

0.9214

2.6276

0

0.6568

0.8557

2.7248

0

0.9589
1.2660

4.3556

0

0.3086
0.4005

1.1208

1

0.9178

3.0275

0

0.5685
0.7004

1.8815

0

0.6065

0.8621

3.3650

0

0.5460

0.7682

2.1415

0.9277

1.1398

2.5771

o

0.4570

0.6415

0.5346

0.8204

1.2732

2.3275

0

0.5566

0.7048

1.6569

0.8220

1.0354

2.6269

0

0.3076

0.3873

1.2527

0.6393

0.8487

2.3468

I

0.5381

0.6719

1.8926

0.8936

1.1224

4.0958

0

1.1317

1.5966

11.3738

1.3738
0

0.7498
0.9889

0.9889
4.0958

1
0.7288

0.9317

3.0319

0

$\begin{array}{lll}0.5132 & 0.2960 & 0.2104 \\ 0.6931 & 0.4735 & 0.3199\end{array}$

2.2762

2

1.582

1.1316

0.8593

2.9412

0.4166

0.5906

1.7629

0

0.7026

4.0000

0

0.4869

0.2889

1.3686

0.4974

6.1638

0.8078

$\begin{array}{lll}0.5708 & 0.4624 & 0.8078\end{array}$

$\begin{array}{lll}1.6709 & 2.0999 & 44.300\end{array}$

0

1

$\begin{array}{lll}0.5882 & 0.5201 & 2.6687\end{array}$

$\begin{array}{lll}0.7704 & 0.6939 & 3.9325\end{array}$

$\begin{array}{lll}2.1457 & 2.3369 & 14.7059\end{array}$

0

1

0.5889

$\begin{array}{ll}0.2064 & 0.5554 \\ 0.2857 & 0.7450 \\ 0.7090 & 2.2754\end{array}$

$\begin{array}{lll}2.0616 & 0.7090 & 2.2754\end{array}$

1

0

$\begin{array}{cc}0.1998 & 0.6305 \\ 0.2458 & 1.1699 \\ 0.6484 & 6.3722\end{array}$

3.7168

2

0.6004

0.8017

0.3112

0.4740

0.7085

6

0

11 
Table 3. Volatility of Monthly Exchange Rates

\begin{tabular}{|c|c|c|c|c|c|c|c|c|}
\hline (end -of-month exchange rate) & $\begin{array}{c}\text { Germany } \\
\text { DM NS dollar }\end{array}$ & $\begin{array}{c}\text { Japan } \\
\text { yen/USdollax }\end{array}$ & $\begin{array}{c}\text { UK } \\
\text { pound/USdollar }\end{array}$ & $\begin{array}{c}\text { Canada } \\
\text { Cansius dollar }\end{array}$ & $\begin{array}{c}\text { Australia } \\
\text { ASUS dollar }\end{array}$ & $\begin{array}{l}\text { New Zealand } \\
\text { NZS/US dollar }\end{array}$ & $\begin{array}{l}\text { France } \\
\text { FFr/DM }\end{array}$ & $\begin{array}{c}\text { Mexico } \\
\text { peso/US dollar }\end{array}$ \\
\hline \multicolumn{9}{|l|}{1991} \\
\hline Number of obs. & 12 & & & & & & & \\
\hline Mean absolute percentage change & 3.3509 & 1.7903 & 3.0408 & 0.8385 & 1.4008 & 1.2110 & 0.2784 & 0.3922 \\
\hline Standard deviation of pet. chge & 5.1158 & 2.6926 & 4.4050 & 0.9610 & 1.7454 & 1.4713 & 0.3518 & 0.2372 \\
\hline Maximum absolute pet. chge & 12.9457 & 6.8182 & 10.5445 & 1.8509 & 3.2903 & 3.9749 & 0.5978 & 0.5984 \\
\hline Minimum absolute pet. chge & 0.2544 & 0.0000 & 0.0877 & 0.2794 & 0.0255 & 0.0500 & 0.0236 & 0.1878 \\
\hline \multicolumn{9}{|l|}{1992} \\
\hline Number of obs. & 12 & & & & & & & \\
\hline Mean absolute percentuge change & 3.2771 & 2.0783 & 4.1578 & 1.3930 & 1.4079 & 0.9990 & 0.4475 & 0.5079 \\
\hline Standard deviation of pet. chge & 4.3586 & 2.5664 & 5.6491 & 1.7522 & 1.6783 & 1.2895 & 0.5343 & 0.6549 \\
\hline Muximum absolute pet. chge & 9.0612 & 3.9326 & 13.6201 & 4.4177 & 4.3174 & 2.3689 & 0.8763 & 1.1572 \\
\hline Minimum absolute pet. chge & 0.0284 & 0.0401 & 0.4762 & 0.5042 & 0.0527 & 0.0183 & 0.0984 & 0.0163 \\
\hline \multicolumn{9}{|l|}{1993} \\
\hline Number of obs. & 12 & & & & & & & \\
\hline Mean absolute percentage change & 2.6266 & 2.0684 & 2.1527 & 0.9646 & 2.2055 & 1.1803 & 0.7765 & 0.3294 \\
\hline Standard deviation of pet. chge & 3.0404 & 2.6082 & 2.9448 & 1.2106 & 2.6574 & 1.2989 & 1.0415 & 0.4111 \\
\hline Maximum absolute pct. chge & 5.9097 & 5.5377 & 5,3288 & 2.8580 & 5.1263 & 2.5948 & 1.7822 & 0.8176 \\
\hline Minimum absolute pet. chge & 0.8733 & 0.1202 & 0.0135 & 0.0787 & 0.6992 & 0.1846 & 0.0807 & 0.0515 \\
\hline \multicolumn{9}{|l|}{1994} \\
\hline Number of obs. & 12 & & & & & & & \\
\hline Mean absolute percentage change & 1.6826 & 1.7654 & 1.3936 & 1.0605 & 1.7563 & 1.5685 & 0.2917 & 5.3873 \\
\hline excluding December & & & & & & & & 1.4999 \\
\hline Standard devintion of pct. chge & 1.8524 & 2.3000 & 1.8476 & 1.3314 & 1.9837 & 1.4846 & 0.3270 & 13.7661 \\
\hline excluding December & & & & & & & & 2.0748 \\
\hline Maximum absolute pet. chge & 3.8889 & 5.2320 & 3.8080 & 2.3447 & 4.7947 & 2.7501 & 0.6299 & 48.1481 \\
\hline Minimum absolute pct. chge & 0.0251 & 0.2005 & 0,0000 & 0.0651 & 0.3907 & 0.0831 & 0.0734 & 0.0322 \\
\hline 1995 & & & & & & & & \\
\hline Number of obs. & 12 & & & & & & & \\
\hline Mean absolute percentage change & 2.0075 & 3.4603 & 1.2954 & 0.8516 & 1.4847 & 1.2757 & 0.8324 & 6.2493 \\
\hline Standard deviation of pet. chge & 2.9102 & $\$ .1158$ & 1.6821 & 1.1934 & 1.9293 & 1.7951 & 1.0007 & 7.2188 \\
\hline Maximum absolute pet, chge & 6.2296 & 12.0660 & 3.2206 & 2.8163 & 4.1007 & 3.6220 & 1.5444 & 13.5294 \\
\hline Minimum absolute pct. chge & 0.1807 & 0.1475 & 0.0310 & 0.0596 & 0.2115 & 0.0468 & 0.0859 & 0.9677 \\
\hline \multicolumn{9}{|l|}{1996} \\
\hline Number of obs. & 12 & & & & & & & \\
\hline Mean absolute percentage change & 1.8336 & 1.8893 & 1.5026 & 0.6650 & 1.3969 & 0.8328 & 0.5663 & 1.6822 \\
\hline Standard deviation of pet. chge & 2.2174 & 2.0307 & 1.8739 & 0.8315 & 1.6273 & 0.7738 & 0.6902 & 2.5443 \\
\hline Maximum absolute pet. chge & 4.0670 & 4.2984 & 4.0536 & 1.5710 & 2.4623 & 2.3023 & 1.1425 & 9.9058 \\
\hline Minimum absolute pet. chge & 0.3073 & 0.0264 & 0.0514 & 0.1320 & 0.0403 & 0.2545 & 0.0172 & 0.0000 \\
\hline \multicolumn{9}{|l|}{1997 (Jan-Nov) } \\
\hline Number of obs. & 11 & & & & & & & \\
\hline Meen ebsolute percentage change & 2.7319 & 3.0889 & 1.5150 & 0.9524 & 2.0314 & 1.4074 & 0.1756 & 1.4737 \\
\hline Standard deviation of pet. chge & 2.9178 & 3.9472 & 2.4033 & 1.1225 & 1.9259 & 1.4046 & 0.2109 & 2.8232 \\
\hline Maximum absolute pet. chge & 5.0685 & 8.1987 & 5.9925 & 1.9682 & 4.5276 & 4.2769 & 0.3881 & 8.3966 \\
\hline Minimum absolure pet. chge & 0.7923 & 0.8678 & 0.0061 & 0.0145 & 0.0403 & 0.1448 & 0.0245 & 0.0639 \\
\hline \multicolumn{9}{|l|}{1991 - $19971 /$} \\
\hline Number of obs. & 83 & & & & & & & \\
\hline Mew absolute percentage change & 2.4987 & 2.2964 & 2.1588 & 0.9609 & 1.6647 & 1.2083 & 0.4849 & 2.2987 \\
\hline Standard deviation of pet. chge & 3.3278 & 3.1635 & 3.2697 & 1.2305 & 2.0446 & 1.5612 & 0.6511 & 6.1610 \\
\hline Maximum absolute pet. chge & 12.9457 & 12.0660 & 13.6201 & 4.4177 & $\$ .1263$ & 4.2769 & 1.7822 & 48.1481 \\
\hline Minimum absolute pct. chge & 0.0251 & 0.0000 & 0.0000 & 0.0145 & 0.0255 & 0.0183 & 0.0172 & 0.0000 \\
\hline
\end{tabular}




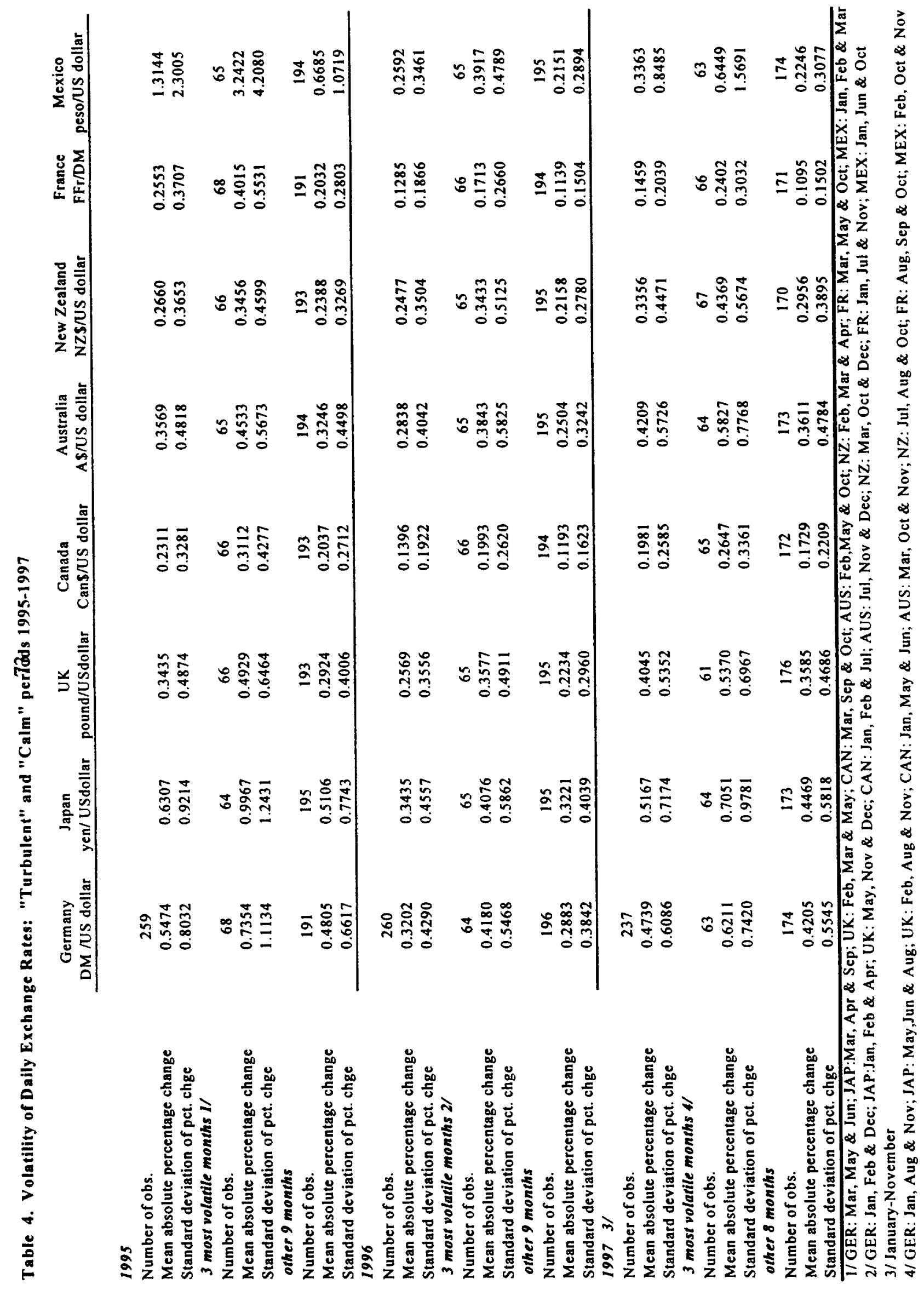


Table 5. Fundamental Volatility of the Mexican peso, 1991-97 (monthly data)

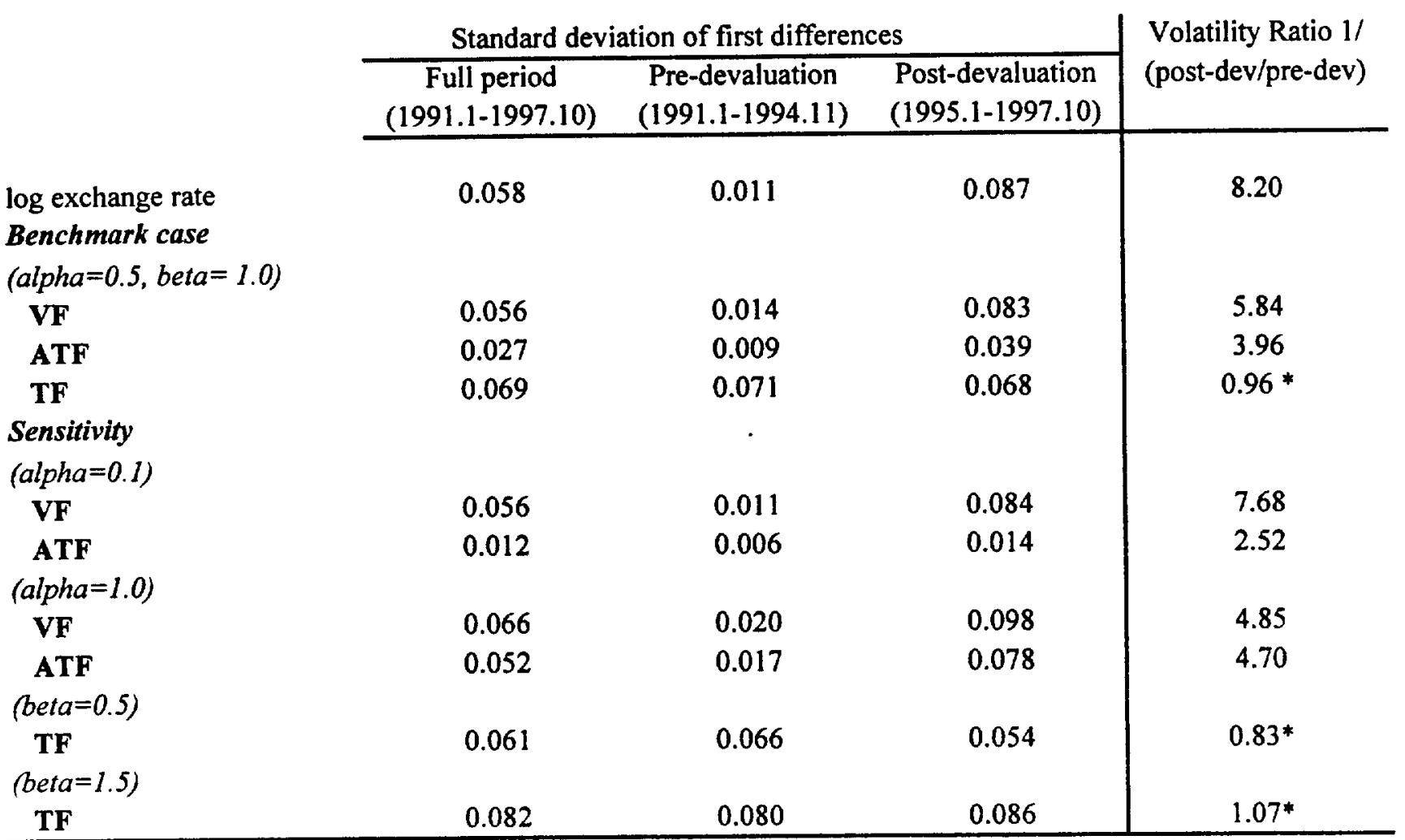

1/ Ratio of sample standard deviations for the two sub-periods. The asterisk indicates that the null hypothesis of equal volatility in the two sub-periods cannot be rejected at the 0.05 confidence level $(0.05$ critical value for $F(30,50)$ is 1.7$)$. 
Table 6

ADE Unit Root Tests

(Weekly Data: January 1996-December 1997) ${ }^{\text {al }}$

\begin{tabular}{|l|l|c|}
\hline & Levels & First Differences \\
\hline Cetes rate & -2.843 & $-5.012^{* *}$ \\
\hline Peso depreciation & $-3.901^{*}$ & $-7.887^{* *}$ \\
\hline $\log$ (base) & -2.589 & $-4.718^{* *}$ \\
\hline exliq & $-3.311^{*}$ & $-6.042^{* *}$ \\
\hline USTbill & -3.061 & $-5.571^{* *}$ \\
\hline
\end{tabular}

al All tests included 3 lags and a time trend.

* significant at 5\% level.

** significant at $1 \%$ level. 


\section{Table 7}

Granger "causality" tests: P-values "

\begin{tabular}{|l|c|c|c|}
\hline & Full Sample & Jan 96-Dec 96 & Jan 97 - Nov 97 \\
\hline i does not cause dep & 0.475 & 0.171 & 0.915 \\
dep does not cause i & 0.568 & 0.021 & 0.511 \\
& & & \\
\hline i does not cause lbase & 0.706 & 0.874 & 0.380 \\
lbase does not cause i & 0.925 & 0.111 & 0.948 \\
& & & \\
\hline i does not cause exliq & 0.504 & 0.720 & 0.990 \\
exliq does not cause i & 0.423 & 0.703 & 0.162 \\
& & & 0.841 \\
\hline dep does not cause lbase & 0.656 & 0.960 & 0.049 \\
lbase does not cause dep & 0.427 & 0.801 & 0.126 \\
\hline dep does not cause exliq & & & 0.313 \\
exliq does not cause dep & 0.071 & 0.307 & 0.893 \\
\end{tabular}

21 Variables have been differenced as needed, to make them stationary. All tests were conducted using 7 lags. 


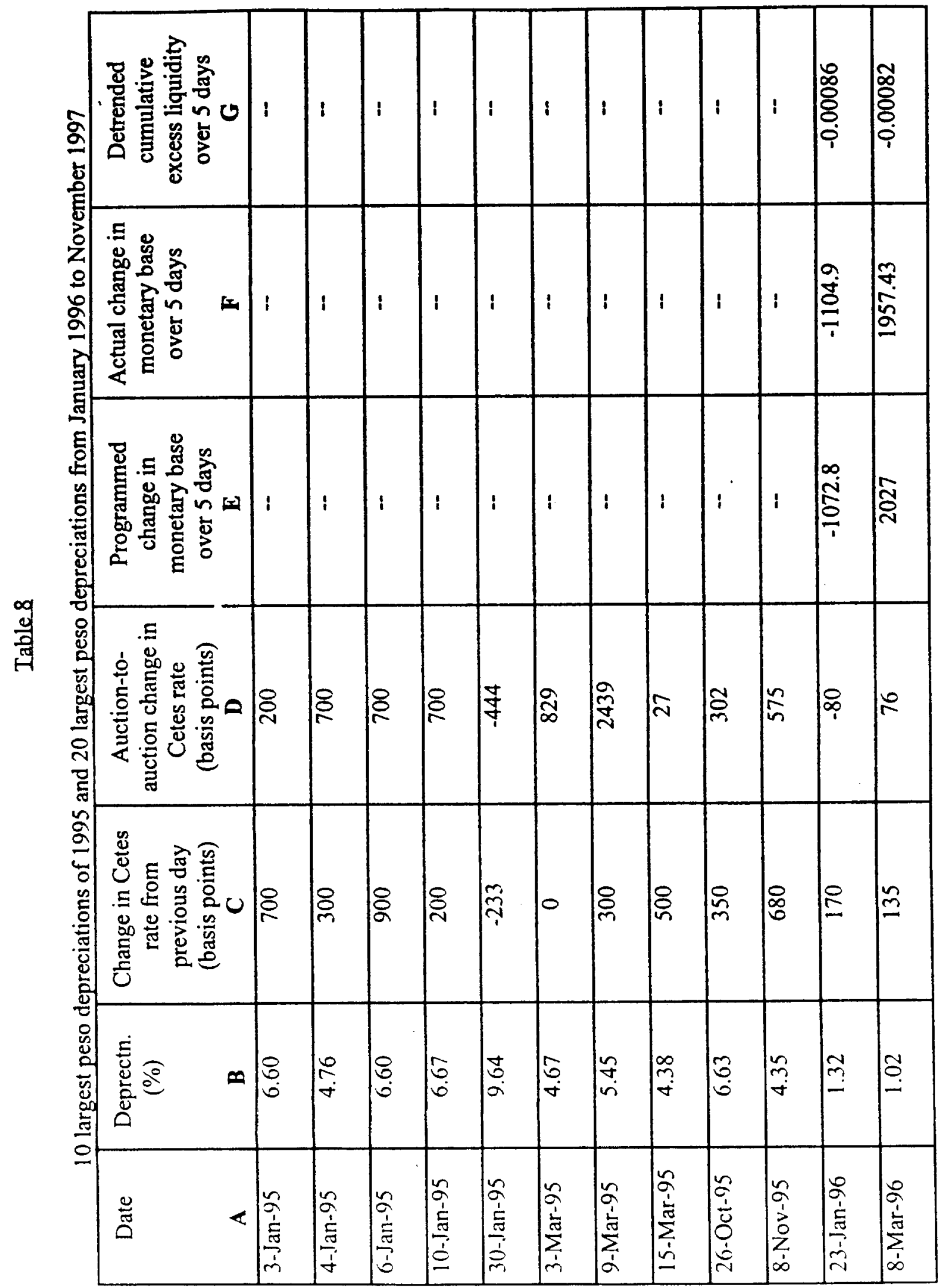




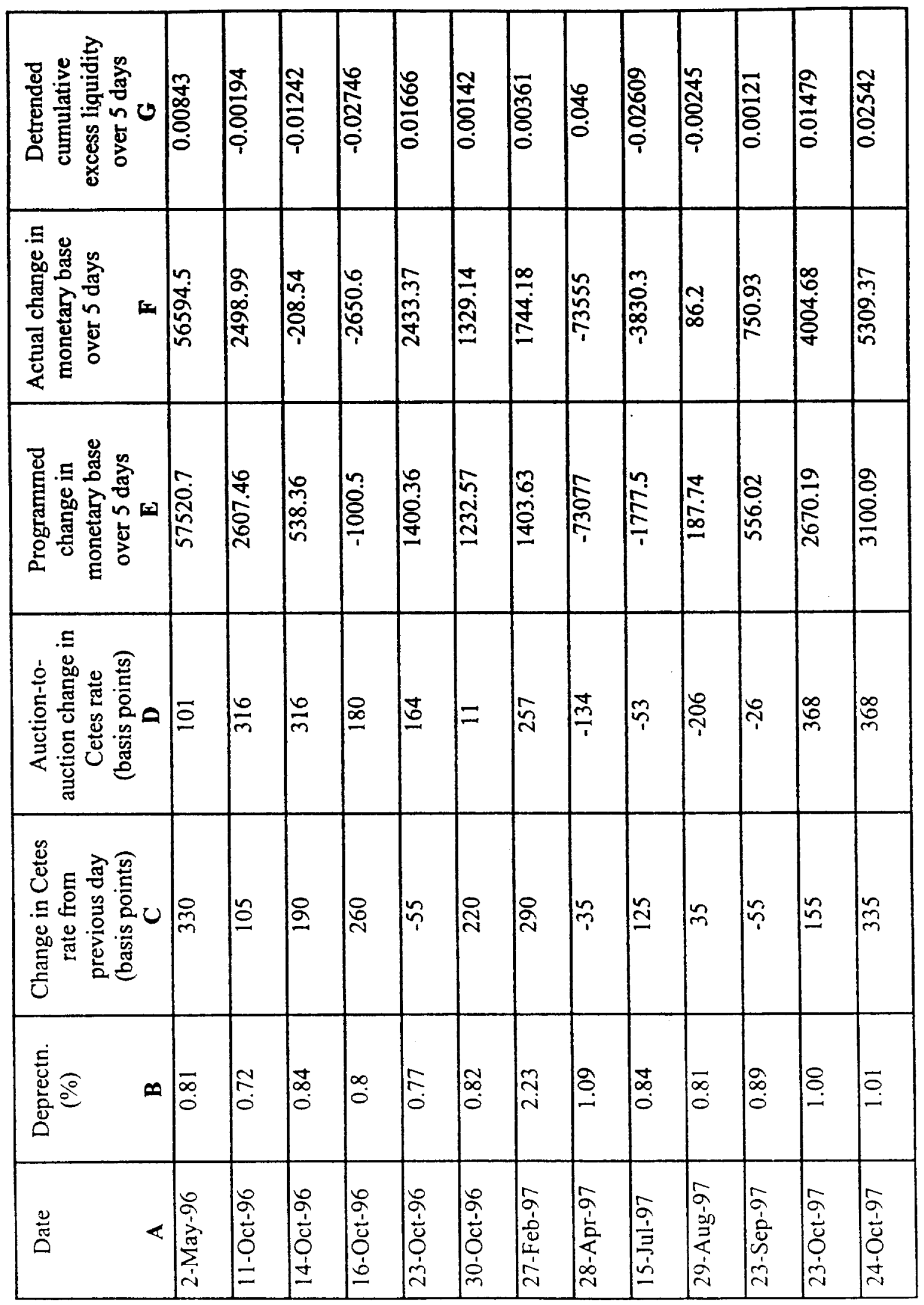




\begin{tabular}{|c|c|c|c|c|c|}
\hline 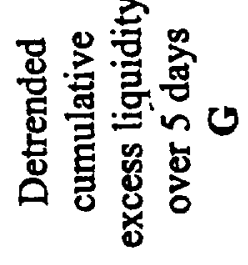 & 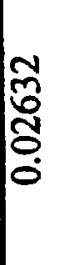 & $\mid \begin{array}{l}1 \\
0 \\
0 \\
0 \\
0 \\
0 \\
0\end{array}$ & 售 & 竞 & 䓂 \\
\hline 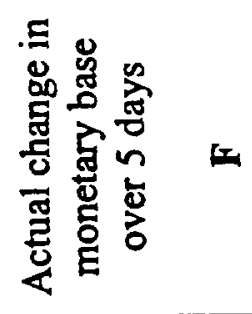 & 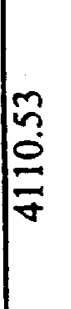 & $\frac{N}{\mathrm{~N}}$ & 䓍 & 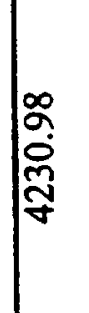 & 容 \\
\hline 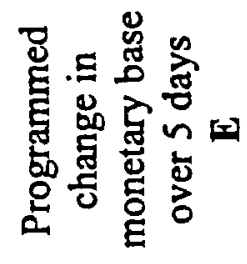 & 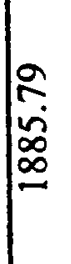 & 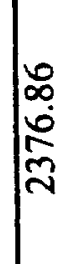 & $\mid \begin{array}{l}\vec{n} \\
\infty \\
m \\
m \\
m\end{array}$ & 落 & 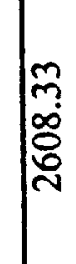 \\
\hline 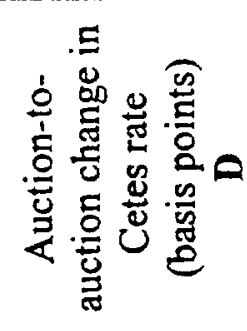 & 然 & 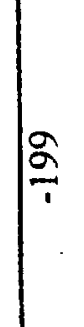 & స్తి & స్ & $\mid \infty$ \\
\hline 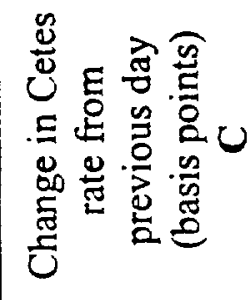 & $\stackrel{n}{m}$ & in & 而 & 弣 & ন \\
\hline 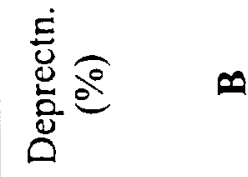 & 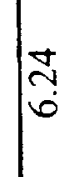 & $\stackrel{\infty}{0}$ & a & 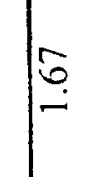 & $\stackrel{\infty}{\stackrel{0}{-}}$ \\
\hline$\frac{\mathscr{J}}{\mathrm{g}}$ & 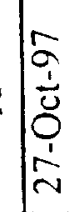 & 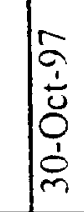 & $\mid \begin{array}{l}a \\
\dot{1} \\
z \\
z \\
b\end{array}$ & 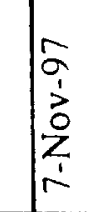 & 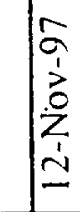 \\
\hline
\end{tabular}


Table 9

Monetary Policy Reaction Function:Weekly Data (OLS)

( $\Delta \log$ Base, dependent variable)

\begin{tabular}{|c|c|c|c|c|c|c|c|}
\hline & Eq 7.1 & Eq 7.2 & Eq 7.3 & Eq 7.4 & Eq 7.5 & Eq 7.6 & $\mathrm{Eq} 7.7$ \\
\hline CONSTANT & $\begin{array}{l}-0.003 \\
(-0.457)\end{array}$ & $\begin{array}{l}-0.001 \\
(-1.747)\end{array}$ & $\begin{array}{l}-0.011 \\
(-2.417)\end{array}$ & $\begin{array}{l}-0.003 \\
(-0.354)\end{array}$ & $\begin{array}{l}-0.009 \\
(-1.737)\end{array}$ & $\begin{array}{l}-0.001 \\
(-0.126)\end{array}$ & $\begin{array}{l}-0.001 \\
(-0.961)\end{array}$ \\
\hline$\Delta$ log target & $\begin{array}{l}1.058 \\
(26.911)\end{array}$ & $\begin{array}{l}1.068 \\
(24.937)\end{array}$ & $\begin{array}{l}1.066 \\
(23.961)\end{array}$ & $\begin{array}{l}1.092 \\
(23.529)\end{array}$ & $\begin{array}{l}1.058 \\
(26.98)\end{array}$ & $\begin{array}{l}1.089 \\
(23.165)\end{array}$ & $\begin{array}{l}1.095 \\
(23.159)\end{array}$ \\
\hline $\begin{array}{l}\left(\text { Log base } t_{t-1}-\right. \\
\left.\log \text { target } t_{t-1}\right)\end{array}$ & $\begin{array}{l}-0.352 \\
(-3.959)\end{array}$ & $\begin{array}{l}-0.420 \\
(-4.221)\end{array}$ & $\begin{array}{l}-0.353 \\
(-3.903)\end{array}$ & $\begin{array}{l}-0.341 \\
(-3.584)\end{array}$ & $\begin{array}{l}-0.356 \\
(-3.977)\end{array}$ & $\begin{array}{l}-0.341 \\
(-3.471)\end{array}$ & $\begin{array}{l}-0.335 \\
(-3.443)\end{array}$ \\
\hline$\Delta \mathrm{i}^{*}{ }_{\mathrm{t}}$ & $\begin{array}{l}-0.015 \\
(-1.369)\end{array}$ & $\begin{array}{c}-0.005 \text { s } \\
(-0.411)\end{array}$ & -- & -- & -- & -- & -- \\
\hline$\Delta \mathrm{i}_{\mathrm{t}-1}$ & $\begin{array}{l}-3.2 \mathrm{E}-4 \\
(-0.490)\end{array}$ & $\begin{array}{l}-0.001 \\
(-0.446)\end{array}$ & -- & -- & -- & -- & -- \\
\hline$\Delta \log s_{t-1}$ & $\begin{array}{l}-0.773 \text { al } \\
(-2.110)\end{array}$ & $\begin{array}{l}-1.284 \\
(-2.269)\end{array}$ & $\begin{array}{l}-1.010 \\
(-2.139)\end{array}$ & -- & -- & -- & $\begin{array}{l}0.879 \\
(0.642)\end{array}$ \\
\hline $\operatorname{Dep}_{t-1}$ & -- & - & -- & $\begin{array}{l}-1.694 \\
(-2.773)\end{array}$ & -- & $\begin{array}{l}-1.834 \text { a } \\
(-1.985)\end{array}$ & $\begin{array}{l}-2.723 \\
(-2.579)\end{array}$ \\
\hline $\operatorname{Int}_{t-1}$ & -- & -- & -- & -- & $\begin{array}{c}-0.031 \\
(-2.424)\end{array}$ & $\begin{array}{c}-1.2 \mathrm{E}-4^{\mathrm{b}} \\
(-0.060)\end{array}$ & -- \\
\hline $\mathrm{R}^{2}$ & 0.92 & 0.92 & 0.91 & 0.912 & 0.911 & 0.911 & 0.910 \\
\hline $\mathrm{F}$ & 113.8 & 82.6 & 142.3 & 122.89 & 141.07 & 90.78 & 90.06 \\
\hline DW & 2.150 & 1.741 & 1.742 & 1.766 & 1.945 & 1.787 & 1.771 \\
\hline $\mathrm{N}$ & 72 & 69 & 71 & 71 & 83 & 71 & 71 \\
\hline
\end{tabular}

Note: t-statistics in parentheses.

All equations included as regressors time and time squared (not reported).

al This figure corresponds to the sum of the coefficients from a second-order seven-lags PDLwith a nearend constraint.

b This figure corresponds to the sum of the coefficients from a second-order four-lags PDLwith a nearend constraint. 
Table 10

Monetary Policy Reaction Function:Weekly Data (Instrumental Variables*)

$\left(\Delta \log\right.$ Base $_{t}$ dependent variable)

\begin{tabular}{|c|c|c|c|c|}
\hline & $\mathrm{Eq} 7.8$ & Eq 7.9 & $\mathrm{Eq} 7.10$ & $\mathrm{Eq} 7.11$ \\
\hline CONSTANT & $\begin{array}{l}7.0 \mathrm{E}-4 \\
(0.795)\end{array}$ & $\begin{array}{l}0.013 \\
(1.253)\end{array}$ & $\begin{array}{l}-0.008 \\
(-1.558)\end{array}$ & $\begin{array}{l}0.006 \\
(0.489)\end{array}$ \\
\hline$\Delta$ log target & $\begin{array}{l}1.138 \\
(19.317)\end{array}$ & $\begin{array}{l}1.169 \\
(17.938)\end{array}$ & $\begin{array}{l}1.060 \\
(26.316)\end{array}$ & $\begin{array}{l}1.187 \\
(12.750)\end{array}$ \\
\hline (Log base $\left._{t-1}-\log \operatorname{target} t-1\right)$ & $\begin{array}{l}-0.331 \\
(-2.579)\end{array}$ & $\begin{array}{l}-0.299 \\
(-2.229)\end{array}$ & $\begin{array}{l}-0.354 \\
(-3.856)\end{array}$ & $\begin{array}{l}-0.287 \\
(-1.932)\end{array}$ \\
\hline$\Delta \log s_{t}$ & $\begin{array}{l}-2.559 \\
(-2.460)\end{array}$ & -- & -- & -- \\
\hline $\operatorname{Dep}_{t-1}$ & - & $\begin{array}{l}-3.332 \\
(-2.652)\end{array}$ & -- & $\begin{array}{l}-5.791 \mathrm{~d} \\
(-1.960)\end{array}$ \\
\hline Int $_{t-1}$ & -- & -- & $\begin{array}{l}-0.027 \\
(-1.858)\end{array}$ & $\begin{array}{l}0.063 \text { b } \\
(1.204)\end{array}$ \\
\hline $\mathrm{R}^{2}$ & 0.877 & 0.892 & 0.909 & 0.888 \\
\hline $\mathrm{F}$ & 91.70 & 101.44 & 134.00 & 72.12 \\
\hline DW & 1.53 & 1.621 & 1.941 & 1.598 \\
\hline $\mathrm{N}$ & 74 & 74 & 83 & 71 \\
\hline
\end{tabular}

Note: $t$-statistics in parentheses.

* The following instruments were used: lagged and twice lagged values of base money growth, contemporaneous through 4 weeks lagged values of target base growth, lagged stock distribution, lagged value of the weekly devaluation, time and time squared.

al This figure corresponds to the sum of the coefficients from a second-order seven-lags PDLwith a nearend constraint.

bl This figure corresponds to the sum of the coefficients from a second-order four-lags PDLwith a nearend constraint. 